\title{
PONTOS QUÂNTICOS AMBIENTALMENTE AMIGÁVEIS: DESTAQUE PARA O ÓXIDO DE ZINCO
}

Crislaine Sandria, Maria Victória Krieger ${ }^{\mathrm{a}}$, Wallison Chaves Costa $^{\mathrm{b}}$, Arleide Rosa da Silva ${ }^{\mathrm{a}}$, Ivan Helmuth Bechtold ${ }^{\mathrm{b}}$ e Lizandra Maria Zimmermann ${ }^{\mathrm{a}, *}$

aDepartamento de Química, Universidade Regional de Blumenau, 89030-903 Blumenau - SC, Brasil

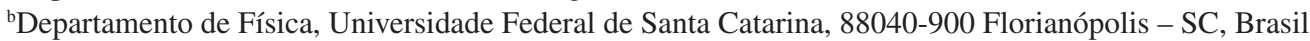

Recebido em 30/03/2017; aceito em 10/07/2017; publicado na web em 29/08/2017

ENVIRONMENTALLY FRIENDLY QUANTUM DOTS: HIGHLIGHTING ZINC OXIDE. Semiconductor nanocrystals with sizes in the quantum confinement regime $(2-10 \mathrm{~nm}$ ) present special physical and chemical properties. Additionally, environment-friendly quantum dots (QDs), as zinc oxide and zinc sulfide, offer many practical usages. Herein the $\mathrm{ZnO}$ semiconductor nanocrystals properties will be preferentially explored, such as its luminescence, broad spectrum UV absorber and electronics performances, and therefore its multifunctionality, as well as its advantages compared to some toxics QDs. A review is carefully presented stressing some synthesis approaches for applications reasons toward devices, chemosensors, biological labels, UV-absorbers and photocatalysis. $\mathrm{ZnO}$ QDs have been used in combination with organic and other inorganic materials. Hybrid materials have many advantages compared to their individual contents leading to important contributions to science and technology. As a result, an important growth in material fields is noticeable.

Keywords: $\mathrm{ZnO}$ quantum dots; environment-friendly quantum dots; photocatalysis; UV-blockers; size-dependent fluorescence emission.

\section{INTRODUÇÃO}

É notória a contribuição da nanotecnologia nas ciências biológicas, farmacêuticas e da saúde nestas últimas três décadas. Como resultado, tem-se observado uma oferta cada vez maior de novos materiais, inteligentes e funcionais, o melhoramento da qualidade de vida das pessoas e, consequentemente, um aumento na expectativa de vida. ${ }^{1}$

No início da década de 1980 apareceram os primeiros estudos para uma nova classe de nanocristais com capacidade de exibir propriedades espectroscópicas dependentes do tamanho, ${ }^{2}$ advindas do efeito de confinamento quântico. ${ }^{3-5} \mathrm{O}$ confinamento quântico é resultado da mudança da densidade dos estados eletrônicos, que por sua vez, está relacionada com a posição e momento para partículas livres e confinadas. Quando a energia e o momento são definidos, a posição destas partículas não pode ser definida com precisão. Se considerada a relação entre energia e momento para a fase sólida massiva, é como pensar que uma série de vibrações que ocorrem com pequenas diferenças de energia nesta fase serão comprimidas, gerando uma transição intensa e única em um ponto quântico (QD, do inglês quantum dot). ${ }^{5}$ Dita de outra maneira, com a redução do tamanho das partículas a excitação eletrônica é deslocada para regiões de maior energia e o oscilador fica com restrita capacidade de transição. A Figura 1 ilustra a densidade de estados partindo de um material massivo, tridimensional (a) e que, progressivamente, sofre o confinamento em uma das dimensões (b)-(d). ${ }^{5}$

QDs podem confinar transportadores de cargas e manter uma coerência de spin destes transportadores em um período de tempo maior que os correspondentes materiais massivos, característica essa fundamental para o desenvolvimento de tecnologia baseada em sistemas quânticos ${ }^{6} \mathrm{e}$ da manifestação de efeitos excitônicos expressivos, os quais dependem da forma e tamanho da estrutura de confinamento. ${ }^{7}$ A incidência de radiação eletromagnética, com comprimento de onda coincidente com o espectro de absorção do QD, pode promover um elétron para a banda de condução, gerando um buraco (teoricamente

*e-mail: lmz@furb.br

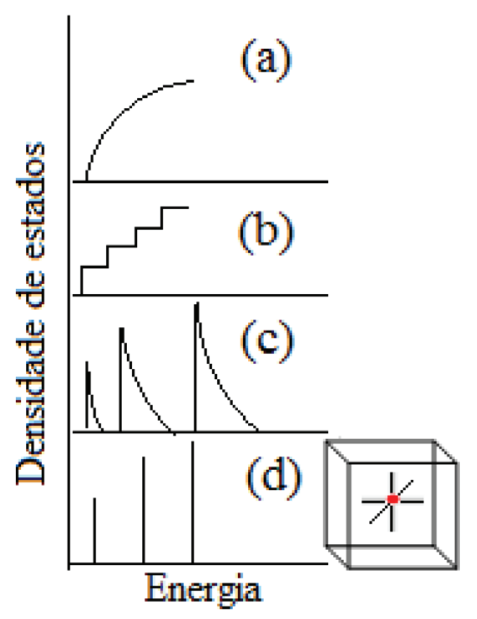

Figura 1. Densidade de estados em uma banda de um semicondutor em função do tamanho e da dimensão: $3 D(a) ; 2 D(b) ; 1 D(c)$ e $0 D(d)$. Adaptada da ref. 5

uma partícula que apresenta carga de sinal oposto ao do elétron) na banda de valência. Nessas circunstâncias, é possível formar um par elétron-buraco chamado de éxciton que se mantém unido graças à atração Coulombiana, sendo considerado uma 'quase-partícula' neutra em um estado excitado. ${ }^{8}$ A recombinação do éxciton pode ser acompanhada de emissão de luz. Para ser considerado um QD, o tamanho do nanocristal de semicondutor deve ser da mesma ordem do raio de Bohr do éxciton. ${ }^{8}$

Os éxcitons possuem relativa liberdade de movimento e a energia de ligação fica abaixo do limite de dissociação de transportadores de carga livres ou do intervalo entre as bandas de valência e condução (band gap). Para uma porção massiva 3D de CdSe com constante dielétrica de alta frequência, a interação de Coulomb é fortemente blindada e os transportadores apresentam baixa massa efetiva. Nestas circunstâncias, o éxciton apresenta uma energia de ligação de apenas $15 \mathrm{meV}$, bem inferior ao intervalo de bandas que é de $1,84 \mathrm{eV}$ e, por isso, éxcitons dissociam-se em transportadores livres em temperatura ambiente. ${ }^{9}$ 
Se considerada a mesma constante dielétrica para várias dimensionalidades, um sistema bidimensional apresentará a energia de ligação do éxciton e a interação Coulombiana aumentada por, no mínimo, um fator de quatro vezes, quando comparada com o tridimensional. ${ }^{10}$ Quando confinado em uma dimensão, já não existe distinção de estado entre elétrons-buracos livres ou ligados. Por fim, um nanocristal de dimensão zero, elétrons e buracos estão altamente confinados que não existe correlação entre a mobilidade relativa.

O efeito do tamanho em nanocristais semicondutores tem recebido especial atenção, principalmente considerando a região da banda proibida, ou seja, a diferença entre a banda de valência (BV) e a banda de condução (BC). Esta banda aumenta à medida que os QDs tornam-se menores, por conseguinte, diminuindo o comprimento de onda da emissão de fluorescência. Outros aspectos importantes a serem destacados para os QDs estão na interação elétron-elétron que torna-se mais forte, e então podem ser observados efeitos monoeletrônicos, como o bloqueio da interação Coulombiana e mudanças no potencial redox. ${ }^{9}$ Os efeitos excitônicos tornam-se mais pronunciados, permitindo ressonâncias de absorção até mesmo em temperatura ambiente. ${ }^{10}$

Os QDs são nanopartículas (NPs) ou nanocristais de material semicondutor de dimensão que varia de 2 a $10 \mathrm{~nm}$, com elementos do grupo II-VI (CdSe, CdTe, CdS, ZnSe, etc), III-V (InP, InAs), IV-VI ( $\mathrm{PbS}, \mathrm{PbSe}), \mathrm{II}_{3}-\mathrm{V}_{2}\left(\mathrm{Cd}_{3} \mathrm{As}_{2}\right)^{11,12}$ com propriedades distintas, como elevada absorção, fotoestabilidade, larga região do espectro de excitação e estreitas bandas de emissão e baixa tendência de fotodegradação. ${ }^{13}$ Tais comportamentos são fundamentais, por exemplo, para a obtenção de imagens em sistemas biológicos e diagnósticos médicos. Por isso, QDs apresentam inúmeras vantagens em relação as moléculas fluorogênicas individuais. Entretanto, possuem também limitações, como a intermitência da fluorescência em toda a escala temporal. ${ }^{13} \mathrm{O}$ tamanho e a composição química permitem que se obtenha materiais que podem ser excitados em diferentes regiões do espectro. Assim, obtém-se emissão de luz na faixa de 495-515 $\mathrm{nm}$ a partir de nanocristais de CdSe com $2 \mathrm{~nm}$, já quando o tamanho destes nanocristais de mesma natureza química é $5 \mathrm{~nm}$, a emissão é na faixa de 605-630 nm. Essa importante propriedade da emissão de fluorescência dependente do tamanho é ilustrada na Figura 2. ${ }^{14}$

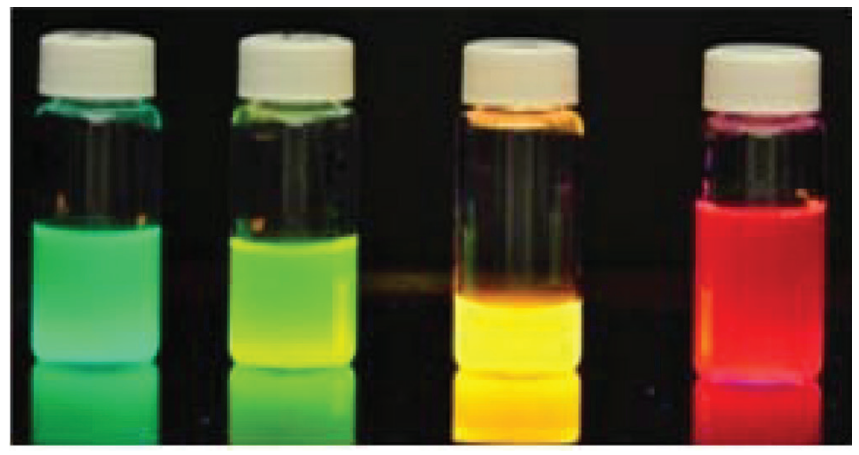

Figura 2. Imagem dos sistemas contendo QDs obtida no laboratório de nanotecnologia e medicina regenerativa de Londres, UK. ${ }^{14}$ Extraído da ref. 14, com permissão da Dove Medical Press Ltd.

Com esse conjunto de características, os nanocristais semicondutores apresentam inúmeras aplicações, tais como: dispositivos emissores de luz (LEDs), ${ }^{15-19}$ lasers,${ }^{3,18}$ computação quântica, ${ }^{20}$ transistores, ${ }^{21}$ células solares, ${ }^{22,23}$ biomedicina e biossensores, ${ }^{24,25} \mathrm{e}$ para sistemas catalíticos diversos, ${ }^{26-28}$ sendo esta última, uma área ainda pouco explorada.

A pesquisa envolvendo QDs instiga para o diálogo entre as várias áreas do conhecimento, destacando a Química, a Física, a Biologia e a Ciência de Materiais. Surgem, então, inúmeras possibilidades para estudo, já que estes nanocristais podem ser obtidos por vários métodos e a partir de diversos elementos. Nesse aspecto, o método sintético, bem como as técnicas de caracterização, tornam-se fundamentais.

Os primeiros sistemas coloidais bem sucedidos de QDs (CdS, $\mathrm{CdSe}, \mathrm{CdTe})^{29}$ apresentavam média e elevada toxicidade, entretanto, ainda são bastante utilizados. ${ }^{30-35}$ Neste ponto, surge a demanda pelo preparo de sistemas livres de materiais tóxicos e, portanto, ecologicamente e ambientalmente toleráveis.

O desafio que reside no planejamento de QDs é combinar propriedades ópticas e eletrônicas desejáveis com a forma, tamanho e controle de superfície. Por exemplo, nas superfícies de semicondutores inorgânicos puros ocorrem reconstruções atômicas com energias dentro da região da banda proibida para o sólido massivo. Estes novos estados de superfície capturam elétrons ou os buracos deixados por estes, degradando, desta forma, as propriedades do material. ${ }^{5}$ Daí decorre a importância do processo de passivação da superfície, que consiste em uma sobrecamada de um material com um band gap maior, livre de tensão, e que promova uma mudança no potencial químico dos elétrons ou dos buracos presentes na interface, eliminando os níveis de energia que ficam entre os intervalos das bandas. ${ }^{5,36}$

A partir dessa problemática este texto será desenvolvido, dando-se ênfase para os QDs ambientalmente amigáveis, suas propriedades, aplicações e os métodos sintéticos de obtenção com destaque para o método sol-gel.

\section{Pontos quânticos ambientalmente amigáveis}

O setor industrial, impulsionado pela necessidade de suprir a grande demanda social de produtos, vem sendo o maior responsável pela exploração inadequada e contaminação dos recursos ambientais. ${ }^{37}$ Nas últimas décadas, o aumento de resíduos e a exposição de materiais tóxicos se tornaram uma preocupação mundial. ${ }^{38} \mathrm{~A}$ necessidade de tornar os processos produtivos mais sustentáveis e de driblar a escassez de diversos materiais, fez com que os estudos de inovação tecnológica fossem repensados no sentido de garantir uma inovação social sustentável. ${ }^{39}$ Nessa perspectiva, exige-se que o progresso da indústria seja aliado ao cuidado com a diminuição dos impactos ambientais. ${ }^{37}$

As pesquisas em nanotecnologia tiveram seu foco inicial no desenvolvimento de novos materiais, aproveitando-se do fato de as nanoestruturas apresentarem propriedades distintas e, consequentemente, pelo potencial de aplicações. Entretanto, a preocupação com os aspectos ambientais, a saúde e a segurança é ainda muito recente..$^{40,41}$ Hutchison ${ }^{40}$ propõe que os estudos envolvendo nanomateriais devam ser orientados pelos princípios da "química verde", através de estratégias que sigam métodos precisos de síntese e purificação, além de uma avaliação rápida dos efeitos biológicos e o estudo mecanístico detalhado desses efeitos.

Pelos mesmos princípios da "química verde", e com o avanço dos estudos na área de nanomateriais, as NPs com elementos, tais como cádmio, telúrio e chumbo, ${ }^{4,42}$ pela toxicidade que apresentam, tendem, quando possível, a ser substituídas por opções ambientalmente corretas. ${ }^{43}$

Breves investigações sobre possíveis impactos ambientais ${ }^{44}$ e efeitos adversos causados em animais em contato com QDs tó$\operatorname{xicos}^{45}$ já foram realizados. A eficiência destas pesquisas ainda é questionável, pois não se tratam de testes direcionados a organismos humanos e as análises ambientais não representam escalas reais. ${ }^{46}$ Algumas alternativas de modificar a superfície das partículas já foram exploradas a fim de tornar os QDs tóxicos compatíveis com aplicações biomédicas. ${ }^{42}$ As substâncias são incorporadas à superfície dos QDs, com o objetivo de garantir a estabilidade das partículas e evitar a degradação que, supostamente, libera íons ao ambiente em que o material é exposto. Os QDs podem ser planejados, de modo 
a possuírem uma camada externa de um material inorgânico, que seja diferente do material inorgânico semicondutor central que está sendo revestido, por isso, chamados de core-shell. Esses sistemas combinados podem ser planejados com uma ou múltiplas camadas. Existem diversas publicações que apresentam sínteses de sistemas core-shell com QDs tóxicos revestidos de materiais não nocivos. Yakoubi e colaboradores ${ }^{47}$ recentemente propuseram a síntese de um sistema core-shell com QDs de $\mathrm{CdZnS}$ dopados com íons cobre (core) e camadas de $\mathrm{ZnS}$ como shell ( $\mathrm{Cu}: \mathrm{CdZnS} / \mathrm{ZnS})$. Os autores reportaram que a adição destas camadas produziu partículas com maior fotoestabilidade e aumento de $9 \%$ para $42 \%$ no rendimento quântico. A passivação da superfície dos QDs diminui a densidade de centros de recombinações não radiativas aumentando a fotoluminescência. Além disso, as camadas de $\mathrm{ZnS}$ isolam o core, inibindo a liberação dos íons cádmio, que fazem com que os QDs sejam potencialmente tóxicos. Os autores justificam que o impedimento da exposição destes íons ao ambiente tornam o material aplicável para área biomédica, inclusive como marcadores biológicos e agentes de contraste.

Embora muitas pesquisas com estes materiais sejam animadoras, existem estudos que provam o contrário. Pleskova e colaboradores ${ }^{48}$ analisaram a interação dos eritrócitos humanos com sistemas core-shell de QDs como CdSe/ZnS, e (CdSe/CdZnS)ZnS e (CdSe/CdS)ZnS, sendo o $\mathrm{ZnS}$ a camada externa, e revestidos ainda com outras moléculas. Os autores alegam que os estudos mostram modificações na morfologia dos eritrócitos causadas pelo contato com as partículas. Estes fatos levam a concluir que a modificação superficial pode não ser tão eficaz como alguns estudos apontam.

Deste cenário advém uma tendência muito grande para explorar as possibilidades de substituição dos QDs tóxicos por aqueles ambientalmente amigáveis. Dentre as diversas opções, pode-se citar: carbono, $\mathrm{SiO}_{2}, \mathrm{Ag}_{2} \mathrm{~S}, \mathrm{TiO}_{2}, \mathrm{ZnS}, \mathrm{ZnO}$, etc.

$\mathrm{ZnS}$ e ZnO são exemplos de QDs de baixa toxicidade que apresentam propriedades interessantes. Ambos os QDs são semicondutores transparentes do tipo II-VI. O ZnS na fase massiva tem um band gap de 3,68 eV com boa emissão na região azul. O confinamento quântico das partículas de $\mathrm{ZnS}$ faz com que o material apresente uma faixa larga de absorção e uma banda estreita de emissão no espectro, além de alta resistência à fotodegradação e um tempo longo de emissão de fluorescência. ${ }^{49-51}$

Já os QDs de ZnO destacam-se, diante de outros materiais, pela sua alta energia de ligação do éxciton, de $60 \mathrm{meV}$ à temperatura ambiente. Na fase massiva, as partículas têm um band gap próximo a 3,37 eV, absorção máxima em $360 \mathrm{~nm}$ com emissão perto de 520 $\mathrm{nm}$, além de ótima estabilidade térmica e mecânica. Uma propriedade muito interessante dos QDs de $\mathrm{ZnO}$ é a capacidade de emitir fluorescência na faixa do azul ao amarelo (dependendo do diâmetro das partículas), diante da excitação com luz ultravioleta (UV). A fotoluminescência dos QDs de $\mathrm{ZnO}$, à temperatura ambiente, consiste basicamente, de duas emissões competitivas: uma na região do UV e a outra na região do visível, na faixa do verde ao amarelo. A emissão no UV é resultado de um efeito excitônico da recombinação de um elétron e um buraco na região de interface das bandas de valência e condução ou pela presença de estados ionizados na superfície. ${ }^{52}$ Já a emissão no visível, com uma banda mais larga, ocorre devido aos defeitos estruturais, tais como as vacâncias de zinco e oxigênio e, ainda, devido às impurezas. ${ }^{53-55}$ Os QDs apresentam propriedades ópticas superiores que os materiais massivos, especialmente devido aos efeitos do confinamento quântico. ${ }^{52}$ Assim, por exemplo, se o mecanismo da fluorescência na região do visível dos QDs de ZnO for devido às vacâncias de oxigênio na superfície, será muito mais pronunciado, comparando-se com o respectivo material massivo, já que a área superficial específica é muito maior para as nanoestruturas. Além disso, os QDs diferenciam-se por apresentarem band gaps de maior energia, variáveis de acordo com o tamanho, deslocamento para o azul no máximo de emissão ${ }^{56}$ e por possuírem bandas de emissão mais estreitas, de cor mais pura. ${ }^{57}$

A emissão pode ser de natureza intrínseca ao material, ou pode ser introduzida por meio de substituições parciais na estrutura cristalina. Liu e colaboradores ${ }^{58}$ sugeriram que defeitos e armadilhas na superfície são responsáveis pela emissão de determinadas cores,${ }^{59} \mathrm{e}$ realizaram experimentos que provaram que a emissão de fluorescência verde e amarela do $\mathrm{ZnO}$ é ocasionada por impurezas ou excesso de oxigênio no meio reacional. Deste modo, as sínteses podem ser elaboradas a partir de diferentes materiais que atuam como impurezas nas partículas de $\mathrm{ZnO}$, como o uso de agentes dopantes com o intuito de ampliar as propriedades.

Devido à alta estabilidade química, o $\mathrm{ZnO}$ possui aplicações com as mais diversas formas, tais como o pó, cristais, coloides ou incorporado em outros materiais. As propriedades de absorção em uma ampla faixa na região do UV e emissão de fluorescência da região do azul ao amarelo, tornam o $\mathrm{ZnO}$ promissor para aplicação em lasers, fotocatálise, células solares, bloqueadores de radiação UV, sensores de gases, etc. Além disso, os QDs de ZnO podem ser preparados em solventes alcoólicos ou em água, tornando possível também a aplicação em áreas que exploram a característica da biocompatibilidade.

A Figura 3 ilustra a atenção crescente que esses QDs de $\mathrm{ZnO}$ e $\mathrm{ZnS}$, acima mencionados, vem recebendo da comunidade científica. Esses trabalhos tratam da proposta de métodos sintéticos,
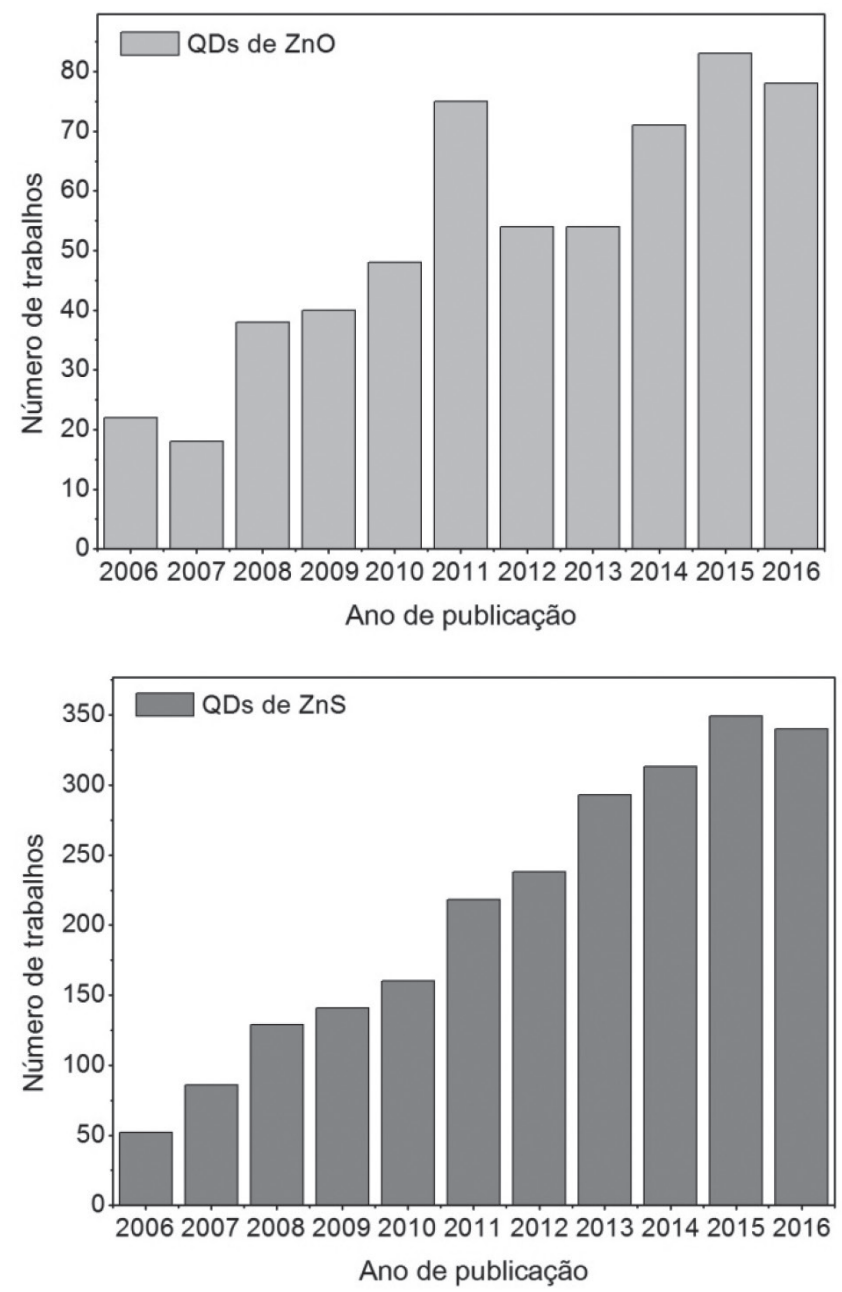

Figura 3. Trabalhos publicados envolvendo as palavras-chave quantum dots de $\mathrm{ZnO}$ e ZnS no período de 2006-2016. As informações foram obtidas com as ferramentas de busca do Web of Science 
caracterizações e aplicações, o que tem representado um avanço muito significativo para a melhoria das propriedades, da estabilidade, do uso e da produção de materiais e tecnologias com QDs ambientalmente amigáveis.

\section{MÉTODOS SINTÉTICOS}

Com a descoberta das promissoras propriedades dos QDs, a comunidade científica vem desenvolvendo e aperfeiçoando vários métodos de sínteses. A escolha da rota sintética para produzir QDs depende de quais características pretendem ser obtidas e para qual aplicação os QDs serão destinados. Um desafio na produção de materiais semicondutores nanocristalinos é, através da síntese, controlar o tamanho e estabilidade das partículas, além de obter uniformidade e pureza nas dispersões. A manipulação destas variáveis é de extrema importância, pois permite a obtenção das propriedades ópticas e elétricas desejáveis dos QDs, como alta luminescência e pureza nas cores de emissão. ${ }^{60-63}$

As sínteses de nanomateriais são subdivididas em duas categorias gerais de métodos, conhecidos como "bottom-up" e "top-down". Este último método, "de cima para baixo", consiste em tentar construir os nanocristais a partir de materiais massivos, ${ }^{64}$ realizando técnicas físicas, como a litografia por feixes de íons ou lasers, ${ }^{63,65,66}$ corrosão por íons reativos, ${ }^{67}$ corrosão química em solução ${ }^{68}$ e eletrodeposição. ${ }^{69}$ Esses métodos trazem vantagens na obtenção de nanomateriais com elevado grau de pureza e são facilmente aplicáveis para produção em larga escala. Em contrapartida, é difícil controlar o tamanho das partículas e obter uma dispersão uniforme, o que pode comprometer as propriedades dos materiais.

Os métodos "bottom-up", "de baixo para cima", produzem materiais a partir de rotas sintéticas em sistemas coloidais, com maior homogeneidade da dispersão. As técnicas de síntese da química coloidal trazem ainda mais vantagens em relação aos métodos "top down", pois além de controlar com maior precisão e uniformidade o tamanho dos nanocristais, permitem modificar a superfície dos QDs no mesmo meio reacional. ${ }^{60-63,65}$ Atualmente, as vias químicas de síntese são as mais utilizadas e estudadas para produção de QDs por envolverem métodos simples, uso de materiais acessíveis de baixo custo. Entre as diversas sínteses reportadas na literatura, algumas se destacam por serem reproduzidas com os precursores em solução, tendo os QDs como a fase coloidal, o que permite controlar a cristalização através dos processos de nucleação e crescimento. ${ }^{60}$ Como exemplos da utilização destes métodos estão as sínteses de redução, ${ }^{70}$ decomposição térmica ${ }^{71}$ e sol-gel. ${ }^{72-74}$

Os semicondutores nanocristalinos da combinação de diferentes grupos da Tabela Periódica, tais como II-VI, III-V e IV-VI, podem ser obtidos por diferentes rotas sintéticas. Os parâmetros que determinam qual a síntese ideal para cada tipo de QD, depende das características desejadas, aplicação dos materiais e a viabilidade. Por exemplo, os QDs de $\mathrm{ZnO}$ podem ser obtidos por métodos “top-down' e "bottom-up", como ablação a laser em fase aquosa, ${ }^{75}$ processo de transporte em fase gasosa ${ }^{76} \mathrm{e}$ deposição química a vapor, ${ }^{77}$ para aplicação destinada em dispositivos optoeletrônicos. Apesar da existência de vários métodos sintéticos, há tendência de utilizar o método sol-gel para a produção de QDs com materiais não tóxicos ${ }^{60}$ principalmente quando se deseja produzir QDs compatíveis com sistemas biológicos, ${ }^{78}$ para aplicação em dispositivos eletrônicos, ${ }^{79} \operatorname{cosméticos},{ }^{80}$ etc. Por isso, o processo sol-gel será explorado com mais detalhes a seguir.

\section{Método sol-gel}

O processo de obtenção de partículas através do método sol-gel, de modo geral, consiste em converter um precursor sólido, composto por um elemento metálico cercado por várias ligações (que não sejam com outros metais), disperso em uma fase líquida, para formação de uma rede cristalina. O termo "sol" é usado para se referir a dispersão coloidal, enquanto o "gel" é dito para a fase final com a estrutura cristalina formada pela agregação das partículas no líquido, embora o método sol-gel possa ser usado para formação de materiais inorgânicos e orgânicos, como vidros, cerâmicas e géis poliméricos. ${ }^{60,65,81-83}$

Para formação de QDs de $\mathrm{ZnO}$, a maioria das sínteses empregam como precursores sais inorgânicos como cloreto e nitrato de zinco, ou sais orgânicos, como é o caso do acetato de zinco di-hidratado. $\mathrm{O}$ processo sol-gel a partir destes sais é realizado em meio aquoso, ou não, a partir de etapas que envolvem reações de hidrólise e condensação, em que primeiro ocorre a nucleação e, por último, a etapa de crescimento das partículas.

A formação de $\mathrm{ZnO}$ é possível quando a esfera de coordenação do metal está saturada, o que pode acontecer de forma espontânea, ou através de catálise, e apresentar diferentes taxas de reação e estruturas do produto condensado. ${ }^{83} \mathrm{~A}$ síntese de QDs de $\mathrm{ZnO}$ é realizada por catálise básica, e dentre as bases mais utilizadas pode-se citar: o hidróxido de sódio, ${ }^{84}$ hidróxido de tetrametilamônio, ${ }^{85}$ hidróxido de potássio ${ }^{86}$ e o hidróxido de lítio. ${ }^{87} \mathrm{Se}$ não houver quantidade necessária de grupos $\mathrm{HO}^{-}$provenientes do solvente ou da base, uma parte das moléculas do sal irá permanecer sem reagir. Desta forma, uma pequena, mas limitada, quantidade de água se faz necessária. A reação química de hidrólise do acetato de zinco, catalisada por hidróxido de sódio, pode ser representada conforme a equação $1.83,88,89$

$$
\mathrm{Zn}\left(\mathrm{CH}_{3} \mathrm{COO}\right)_{2} \cdot 2 \mathrm{H}_{2} \mathrm{O}+\mathrm{NaOH} \rightarrow \mathrm{Zn}(\mathrm{OH})_{2}+\mathrm{NaCH}_{3} \mathrm{COO}+2 \mathrm{H}_{2} \mathrm{O}
$$

Quando o acetato de zinco é dissolvido em solução, gera íons $\mathrm{Zn}^{2+} \mathrm{e} \mathrm{CH}_{3} \mathrm{COO}^{-}$, a base gera os íons $\mathrm{HO}^{-}$e o respectivo cátion. Quando a solução contendo a base é gotejada na solução com acetato de zinco, os íons $\mathrm{Zn}^{2+}$ e $\mathrm{HO}^{-}$colidem-se entre si formando hidróxido de zinco, um acetato com o cátion da base e água. A difusão e a colisão dos íons promovem reações de desidratação, levando à formação dos QDs de ZnO. ${ }^{90}$ Um dos modelos que explica a formação dos QDs segue o processo de nucleação e crescimento de Ostwald ripening. No início da reação, as condições de saturação favorecem a nucleação, que promove o surgimento de uma nova fase sólida, com núcleos de tamanhos diferentes sendo formados simultaneamente, enquanto os menores se dissolvem. Enquanto a formação de pequenos núcleos é favorecida cineticamente, os maiores são termodinamicamente mais estáveis. ${ }^{91}$ Conforme a reação avança o processo de nucleação não é mais favorável devido às mudanças nas condições reacionais, de modo que, com o consumo dos reagentes, há uma diminuição da concentração de íons alterando também o pH da solução. ${ }^{56}$

$\mathrm{O}$ pH da solução é um dos fatores importantes que influenciam diretamente na morfologia, cristalinidade e diâmetro das partículas obtidas pelo método sol-gel. Ao sintetizar $\mathrm{ZnO}$ utilizando acetato de zinco como precursor, em diferentes valores de $\mathrm{pH}$, Alias e colaboradores ${ }^{88}$ observaram diferenças morfológicas nos produtos finais. Em meio ácido ou neutro, a reação leva à formação de aglomerados de partículas na fase bulk. Em condições básicas observou-se o contrário, para o $\mathrm{pH}$ entre 8 e 11 , o $\mathrm{ZnO}$ aglomera-se em esferas nas quais o diâmetro das partículas diminui conforme o aumento do $\mathrm{pH}$. Este fenômeno está associado à concentração de $\mathrm{HO}^{-}$, uma quantidade destes íons é necessária para a dissolução do $\mathrm{ZnO}$, através da formação do complexo $\mathrm{Zn}(\mathrm{OH})_{4}{ }^{2-}$, entretanto, em soluções com $\mathrm{pH}$ maior que 8 , o $\mathrm{Zn}(\mathrm{OH})_{4}^{2-}$ é convertido em $\mathrm{ZnO}$ devido ao alto potencial químico dos íons HO- em equilíbrio com a reação de desidratação, conforme a equação 2. Em meio ácido, a alta concentração de íons $\mathrm{H}^{+}$faz com que o $\mathrm{ZnO}$ dissolva-se em $\mathrm{Zn}^{2+}$ e $\mathrm{H}_{2} \mathrm{O}$ e, deste modo, $\mathrm{ZnO}$ como NPs normalmente não pode ser sintetizado em $\mathrm{pH}$ menor que $8 .{ }^{92}$ 
$\mathrm{ZnO}+\mathrm{H}_{2} \mathrm{O}+2 \mathrm{OH}^{-} \leftrightarrow \mathrm{Zn}(\mathrm{OH})_{4}{ }^{2-}$

Quando o processo de nucleação se estabiliza, favorece o crescimento apenas dos núcleos já formados, produzindo partículas de diâmetros distintos. As reações envolvem vários mecanismos mais complexos, mas de modo simplificado, as etapas de condensação e formação de $\mathrm{ZnO}$ podem ser representadas de acordo com a equação $3 .^{81}$

$\mathrm{Zn}(\mathrm{OH})_{2}+\mathrm{Zn}(\mathrm{OH})_{2} \rightarrow \mathrm{HO}-\mathrm{Zn}-\mathrm{O}-\mathrm{Zn}-\mathrm{OH} \rightarrow \mathrm{ZnO}$ QDs

A quantidade de água e o método de adição são outros fatores que desempenham um papel fundamental nas características morfológicas dos QDs. Lee e colaboradores ${ }^{93}$ estudaram a síntese de NPs de $\mathrm{ZnO}$ controlando o tamanho e o formato das partículas. Os autores argumentam que quanto mais moléculas de água estão hidratando o precursor metálico, maiores tendem a ser as partículas de $\mathrm{ZnO}$. Em meio aquoso, o crescimento dos QDs acontece de forma muita rápida e quase incontrolável, o que leva à formação de partículas com diâmetros que correspondem à fase bulk ou estruturas morfológicas não esféricas. Como alternativas mais eficientes, foram desenvolvidos vários métodos sintéticos para a obtenção de óxidos nanocristalinos por processos sol-gel não aquosos. Estas sínteses podem ser divididas em dois tipos: síntese por controle de surfactantes e síntese por controle de solventes. O primeiro método, também conhecido por injeção a quente, consiste em realizar a injeção de precursores e surfactantes em um solvente aquecido. ${ }^{64}$ Através deste método, Schejn e colaboradores ${ }^{94}$ sintetizaram QDs de $\mathrm{ZnO}$ em microrreatores de processo contínuo. Os autores injetaram os precursores com ácido oleico em etanol variando a temperatura. A presença do ácido oleico como surfactante se mostrou fundamental para controlar o crescimento, obtendo-se partículas com tamanhos distintos pela variação da temperatura de injeção. Embora a injeção a quente seja uma alternativa de sol-gel não aquoso eficaz, a presença de surfactante nem sempre é desejável, tendo em vista a aplicação final dos QDs, por exemplo, quando prejudica a atividade catalítica.$^{64}$ Neste caso, como alternativa utiliza-se a síntese por controle de solvente, a qual permite o uso de diversos solventes orgânicos sem a presença de água. Pinna e Niederberger ${ }^{95}$ obtiveram com sucesso NPs de $\mathrm{ZnO}$ utilizando vários álcoois como solventes, além de acetona, benzilamina, éter dibenzílico e acetonitrila. Embora também classificadas como rota por controle de solvente, o uso de glicóis é conhecido como método poliol. As NPs são sintetizadas com os precursores dissolvidos diretamente em um glicol aquecido ou à temperatura ambiente. QDs de ZnO já foram obtidos, pelo método poliol, utilizando-se o trietilenoglicol, ${ }^{96}$ 1,3-propanodiol, 1,4-butanodiol, 1,5-pentanodiol, 1,6-hexanodiol, etc. ${ }^{97}$

A promissora aplicação de QDs em sistemas biológicos, devido às propriedades de emissão de fluorescência, está impulsionando os pesquisadores para a obtenção de QDs de ZnO compatíveis com sistemas aquosos. A vantagem é que as nanoestruturas de $\mathrm{ZnO}$ apresentam baixa toxicidade e biodegradabilidade..$^{98} \mathrm{O}$ maior desafio de elaborar a síntese em condições não tóxicas é reverter a condição de não estabilidade das NPs de ZnO. A estabilidade está relacionada com o fato de as nanoestruturas, em água, não conseguirem se manter em uma condição permanente de emissão de luminescência, por efeitos na superfície dos QDs. Nos últimos anos, o avanço no conhecimento em NPs permitiu que vários autores desenvolvessem condições e estratégias nas sínteses para a produção de $\mathrm{ZnO}$ com propriedades estáveis. ${ }^{81,99}$ Estas condições são possíveis utilizando-se outras substâncias, durante a síntese, que têm a finalidade de modificar as condições da superfície dos QDs e permitir a emissão de fluorescência em diferentes comprimentos de onda.
O uso do processo sol-gel para síntese de QDs permite que os mesmos sejam obtidos em fase coloidal, ou pela extração do solvente, a obtenção das partículas na fase sólida. Dependendo dos reagentes utilizados durante a síntese, no final é necessário que se faça a purificação da solução através de centrifugação e lavagem com outros solventes, a fim de garantir a estabilidade e propriedades das partículas. ${ }^{89}$ As condições ideais para realizar a síntese, como temperatura, tempo, solvente e escolha dos reagentes, depende do tamanho e das propriedades requeridas.

\section{USO DE QDS E HÍBRIDOS NO PREPARO DE DISPOSITIVOS}

A eletrônica orgânica tem crescido muito nos últimos anos, motivada pelas novas aplicações em dispositivos, impensáveis pela eletrônica tradicional baseada no silício como semicondutor inorgânico. $O$ interesse nos semicondutores orgânicos é impulsionado pela premissa da facilidade de processamento através de métodos como impressão ou deposição por solução/evaporação, versatilidade dos processos de síntese e compatibilidade com uma vasta gama de substratos, tais como os vidros transparentes e materiais poliméricos flexíveis. ${ }^{100-102}$ Todos estes aspectos tornam possíveis aplicações em monitores e displays flexíveis e células solares capazes de revestir mochilas e guarda-sóis.

Dentre os semicondutores orgânicos utilizados estão os polímeros $^{103} \mathrm{e}$ alguns sistemas moleculares, dentre eles destacam-se os cristais líquidos. ${ }^{104,105} \mathrm{~A}$ grande vantagem é que os cristais líquidos aliam a organização molecular dos sistemas cristalinos, necessária ao trânsito das cargas, à fluidez de um líquido, facilitando o processamento do material. Além disso, outra característica importante dos cristais líquidos é a resposta a estímulos externos, sendo possível modificar seu empacotamento e organização molecular, e com isso otimizar e controlar as suas propriedades condutoras. ${ }^{106,107}$

Os QDs vêm despontando para aplicações em dispositivos, pelas suas características únicas, já citadas anteriormente. Entretanto, é muito comum estes dispositivos serem propostos pela combinação de materiais orgânicos e inorgânicos. Abaixo serão discutidos os avanços envolvendo QDs, em especial de $\mathrm{ZnO}$, aplicados como camada ativa em diodos emissores de luz (LEDs), células solares e transistores de efeito de campo (FETs).

\section{Diodos Emissores de Luz - LEDs}

LEDs que utilizam pontos quânticos (QD-LEDs) vêm obtendo excelente desempenho nos últimos anos em relação às tecnologias LED convencionais e LEDs orgânicos (OLEDs) em termos de pureza da cor elevada, estabilidade, baixo custo de produção e a possibilidade de ajuste de comprimento de onda de emissão, controlando-se o tamanho dos QDs, mantendo níveis semelhantes de eficiência. ${ }^{15,108,109}$

Como mencionado acima, NPs de $\mathrm{ZnO}$ têm sido consideradas boas candidatas para o desenvolvimento de dispositivos optoeletrônicos devido seu band gap direto de 3,37 eV à temperatura ambiente e pela alta energia de ligação do éxciton de $60 \mathrm{meV}$. As NPs de $\mathrm{ZnO}$ são uma alternativa ideal à camada transportadora de elétrons devido à sua estabilidade térmica e menor sensibilidade ao oxigênio e à umidade. Além disso, o $\mathrm{ZnO}$ tem maior mobilidade de elétrons do que os semicondutores orgânicos. $O$ transporte mais eficiente de elétrons equilibra a quantidade de buracos e elétrons na camada ativa e, consequentemente, aumenta a taxa de recombinação do dispositivo. ${ }^{110}$

Uma das principais aplicações de QD-LEDs é a construção de LEDs brancos (WLEDs). O primeiro estudo de WLEDs utilizando camadas híbridas de QDs de $\mathrm{ZnO}$ e $\mathrm{SiO}_{2}$ foi descrito em 2008 por Rao e colaboradores, no qual ficou evidenciado que os nanocompósitos 
$\mathrm{ZnO} / \mathrm{SiO}_{2}$, sintetizados pelo método de sol-gel, e com uma composição otimizada de $\mathrm{ZnO}$, produz luz branca a partir de uma fonte de excitação de LED em 404 e $465 \mathrm{~nm}$. O material se mostrou como um potencial candidato para fonte de luz de estado sólido. ${ }^{111} \mathrm{Em}$ 2009, Tae Whan Kim e colaboladores estudaram WLEDs utilizando polímeros híbridos de polivinilcarbazol (PVK) e polimetilmetacrilato (PMMA) e QDs coloidais de ZnO, e concluíram que os QDs de $\mathrm{ZnO}$ adsorvidos na superfície do polímero PVK, atuando como uma camada transportadora de buracos, contribuíam predominantemente para o processo de eletroluminescência dos WLEDs. ${ }^{12}$

Nathan e sua equipe fizeram o primeiro trabalho com uso de NPs de $\mathrm{ZnO}$ como emissores de luz azul para obter um QD-LED branco, ${ }^{113}$ no qual utilizaram o híbrido $\mathrm{ZnO} / \mathrm{TiO}_{2}$, obtido em dispersão coloidal, como camada transportadora de elétrons e QDs de $\mathrm{ZnCdSeS}$, emissores na região do amarelo. A emissão branca é obtida integrando a emissão amarela e a emissão azul a partir da camada híbrida de $\mathrm{ZnO} /$ $\mathrm{TiO}_{2}$. Este dispositivo atingiu uma luminância máxima de $730 \mathrm{~cd} \mathrm{~m}^{-2}$, principalmente pela baixa corrente de fuga do dispositivo com a camada de $\mathrm{ZnO} / \mathrm{TiO}_{2}$ e pela estabilidade frente ao oxigênio e à umidade.

A Figura 4(A) ilustra a estrutura básica de um LED contendo QDs como camada ativa. Consiste de uma sobreposição de camadas de filmes finos com a camada ativa de QDs entre uma camada transportadora de buracos (HTL - Hole Transport Layer) e uma camada transportadora de elétrons (ETL - Electron Transport Layer), além do ânodo transparente de óxido de índio-estanho (ITO), por onde sai a luz, e um cátodo metálico (alumínio). Para melhora da eficiência do dispositivo, camadas adicionais podem ser inseridas, como camadas bloqueadoras de elétrons e buracos.

Neste dispositivo, a partir da escolha adequada dos materiais para reduzir as barreiras de injeção, com aplicação de potencial direto (positivo no ITO e negativo no $\mathrm{Al}$ ) portadores de carga positiva (buracos) e negativa (elétrons) são injetados a partir do ânodo e do cátodo, respectivamente. Na situação ideal, o transporte ocorre de forma equilibrada através das camadas HTL e ETL para formação do par elétron-buraco e consequente recombinação na camada ativa de QDs, resultando na emissão de luz, como mostra o diagrama de energia na Figura 4(B).

\section{Células solares}

No campo de células solares, os QDs vêm sendo utilizados com a finalidade de melhorar a eficiência de conversão de energia solar em eletricidade (PCE, do inglês Power Conversion Efficiency), dadas as propriedades únicas destes materiais, já relatadas acima. ${ }^{115-117}$ Entre todas estas vantagens, a construção de células solares de baixo custo e alta eficiência tem sido de particular interesse devido ao seu potencial para atender às crescentes demandas sociais de recursos energéticos limpos e sustentáveis.

Células solares que utilizam QDs de ZnO têm sido investigadas ao longo dos últimos anos, ${ }^{118-120}$ devido às vantagens que este material apresenta quando comparado com o filme de $\mathrm{TiO}_{2}$, comumente utilizado para este fim. $\mathrm{O} \mathrm{ZnO}$ tem uma maior mobilidade eletrônica e, além disso, pode apresentar estruturas anisotrópicas (como nanofios, nanobastões e nanotubos), resultando em propriedades eletrônicas e ópticas únicas. ${ }^{121,122}$ As células solares baseadas em QDs de $\mathrm{ZnO}$ já atingiram um PCE de $15,49 \%$. $^{123}$

Vitoreti e colaboradores ${ }^{124}$ publicaram, recentemente, um artigo de revisão sobre células solares sensibilizadas por QDs, retratando muito bem o estado da arte para esta aplicação.

A Figura 5(A) ilustra a arquitetura de uma célula solar sólida de bicamada ou homojunção $p$ - $n$, isto é, contendo uma camada de QD tipo- $p$ (doador de elétrons) e QD tipo- $n$ (aceitador de elétrons). Esta bicamada está entre dois eletrodos dissimilares, sendo que um deles deve ser transparente (ITO) para permitir a incidência de luz nas camadas ativas de QD. O diagrama de energia para este dispositivo é mostrado na Figura 5(B).

É fácil de perceber que a célula solar atua de forma inversa ao LED (Figura 4), em que o objetivo é que a luz seja absorvida pela camada ativa e, através de alguns processos internos de separação e extração de cargas, uma corrente elétrica seja gerada.

$\mathrm{O}$ efeito fotovoltaico inicia pela absorção de um fóton, quando o espectro de radiação da luz incidente coincidir com a banda de absorção da camada ativa, promovendo a excitação de um elétron da BV para a BC e gerando um par elétron-buraco (éxciton). Como indicado na Figura 5(B), esse processo pode ocorrer tanto no QD tipo- $p$ como no QD tipo- $n$. O processo seguinte é evitar que a recombinação do éxciton ocorra, gerando emissão de luz. Em células solares sólidas o efeito de recombinação é o maior vilão para diminuição da eficiência do dispositivo. A separação de cargas ocorre na interface entre os dois materiais (doador e aceitador de elétrons), mas para isso o éxciton precisa ser gerado a uma distância da interface menor que o comprimento de difusão do éxciton, que é a distância que ele pode se mover antes de recombinar. Por esse motivo, a área de contato entre doador/aceitador deve ser grande e a distância entre eles pequena. Entretanto, a redução da espessura das camadas tipo- $p$ e tipo- $n$ implica na redução da absorção de luz e, consequentemente, redução na formação de éxcitons. Por fim, as cargas separadas precisam ser eficientemente transportadas ao longo da camada ativa e para isso a mobilidade de elétrons e buracos precisa ser alta através do aceitador e doador de elétrons, respectivamente. Além disso, as
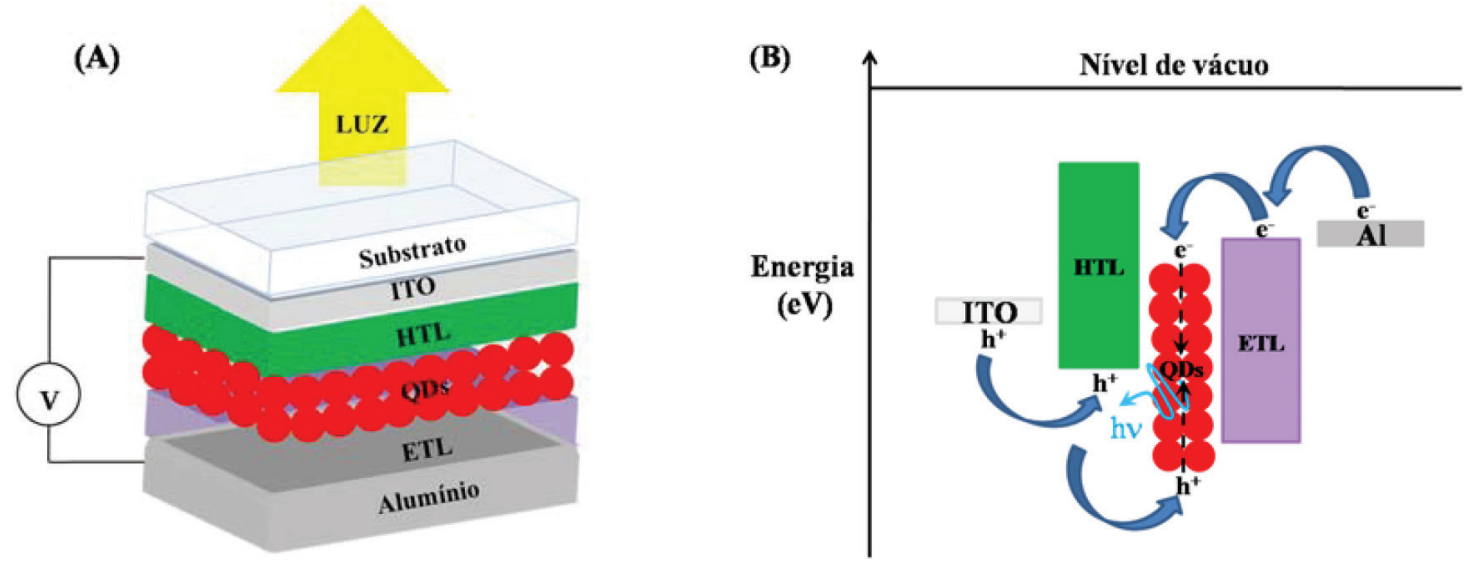

Figura 4. (A) Arquitetura de um LED usando QDs como camada ativa. (B) O diagrama de energia para este tipo de dispositivo. A injeção e transporte de buracos $\left(h^{+}\right)$e elétrons ( $\left.e^{-}\right)$dentro do dispositivo sob aplicação de um potencial elétrico externo são mostrados. Adaptado das refs. 15 e 114 

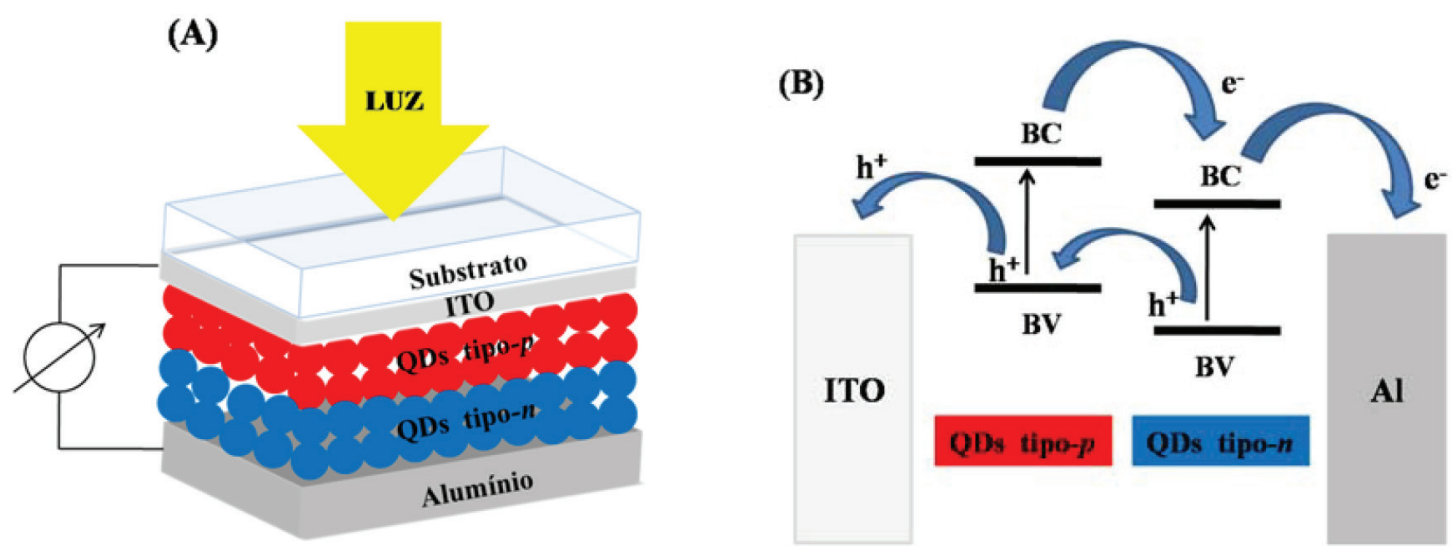

Figura 5. (A) Arquitetura de uma célula solar sólida de bicamada de QD. (B) Diagrama de energia para este tipo de dispositivo. $e^{-}$(elétrons) e $h^{+}($buracos) dissociados movendo-se dentro da BC e BV dos QDs, respectivamente. Adaptado da ref. 125

funções trabalho de ambos os eletrodos precisam ser otimizadas para reduzir as barreiras para extração das cargas.

A eficiência deste tipo de estrutura é limitada pela área de contato relativamente pequena e a grande distância entre as camadas doadora e aceitadora de elétrons. Em virtude disso, a arquitetura de heterojunção de volume de doador e aceitador foi proposta, gerando uma blenda entre os dois materiais e criando canais interdigitados. Em 2013, uma célula solar de heterojunção de $\mathrm{ZnO}$ com PbS alcançou $8,55 \%$ de eficiência. ${ }^{126}$

\section{Transistores de Efeito de Campo - FETs}

QDs também têm sido usados para uma gama de aplicações em transistores de efeito de campo (FETs) com objetivo de evitar a corrente elétrica de fuga através da base do transistor (porta), com intuito de diminuir o seu aquecimento e amplificar os sinais elétricos. ${ }^{127-129}$

Um FET apresenta duas interfaces do filme fino de QD semicondutor que afetam substancialmente o desempenho do dispositivo: com a camada dielétrica colocada entre o eletrodo de porta (gate); com os eletrodos de fonte (source) e de dreno (drain). A Figura 6(A) ilustra um dispositivo FET com QD como camada semicondutora na arquitetura bottom-gate, bottom-contact, na qual o eletrodo porta está na base do transistor recoberto com a camada dielétrica e os eletrodos fonte e dreno depositados sobre a camada dielétrica. O filme semicondutor é depositado sobre este dispositivo já pronto, formando na base a interface com o dielétrico e na lateral com os eletrodos fonte e dreno (em geral de ouro). A região entre os eletrodos da fonte e dreno, preenchida pelo semicondutor, é chamada de canal do transistor.

Quando uma tensão $\mathrm{V}_{\mathrm{G}}$ é aplicada entre o eletrodo de fonte e o eletrodo de porta, origina-se um campo elétrico através do dielétrico, o qual induz acúmulo de cargas na interface QD-dielétrico que depende da intensidade de $\mathrm{V}_{\mathrm{G}}$. Estas cargas podem fluir através do semicondutor mediante aplicação de um potencial $V_{D}$ entre os eletrodos fonte e dreno, resultando numa corrente $I_{D}$. A tensão aplicada ao eletrodo de porta $V_{G}$ controla a corrente $I_{D}$ entre os eletrodos fonte e dreno, pois ela interfere diretamente na densidade de cargas na interface QD-dielétrico ao longo do canal do transistor.

Dependendo da natureza dos QDs e dos eletrodos usados, o canal formado pode ser do tipo- $p$, em que os buracos são os portadores de carga majoritários, ou do tipo- $n$, em que os elétrons são os portadores de carga majoritários. Na Figura 6(B) está ilustrada a configuração em termos de níveis de energia do semicondutor e dos eletrodos

(B)

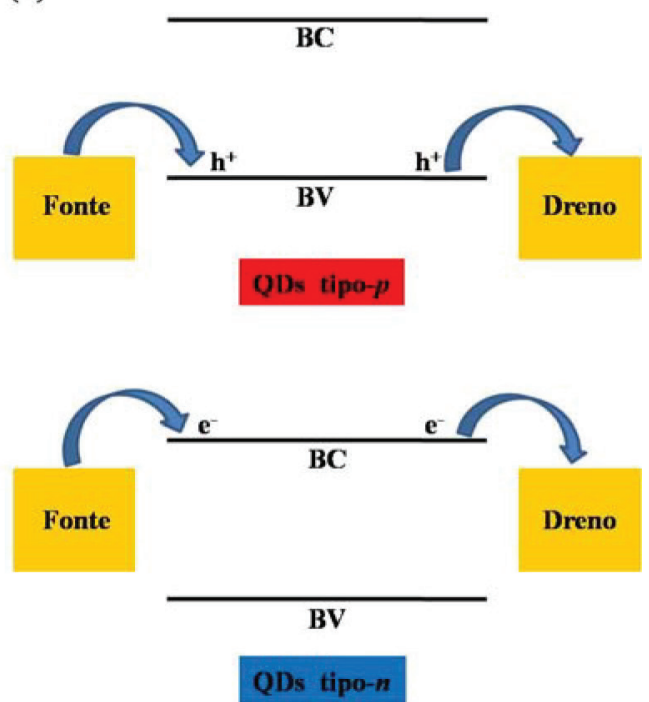

Figura 6. (A) Estrutura básica de um FET usando QDS com geometria bottom-gate, bottom-contact. $V_{G}$ e $V_{D}$ são os potenciais aplicados entre os eletrodos fonte-porta e fonte-dreno, respectivamente. $I_{D}$ é a corrente de operação do transistor entre os eletrodos fonte e dreno. (B) Configuração de níveis de energia do semicondutor e os eletrodos fonte e dreno para um transistor tipo-p (superior) e tipo-n (inferior). Adaptado da ref. 19 
fonte e dreno para um transistor tipo- $p$ (superior) e tipo- $n$ (inferior). No transistor com QDs tipo- $p$ a condução dos buracos ocorre na BV, enquanto que com QDs tipo- $n$ a condução de elétrons ocorre na BC. Em ambos os casos, estas bandas precisam estar devidamente alinhadas com as funções trabalho dos eletrodos para reduzir as barreiras de injeção/extração de cargas e aumentar a eficiência do dispositivo.

Para a formação de uma camada semicondutora transparente no canal do transistor baseada em QDs, essencial para aplicação em dispositivos transparentes, o $\mathrm{ZnO}$ é um dos candidatos que atraem muita atenção. Além disso, apresenta alta mobilidade de efeito de campo em virtude de sua uniformidade e estabilidade em temperatura ambiente. O ZnO ainda é compatível com o processo de fabricação de FETs convencional de $\mathrm{Si}$ e o processo de deposição à baixa temperatura utilizada para eletrônica flexível. ${ }^{130,131}$

Em um estudo feito por Yang e colaboradores, ${ }^{132}$ foram sintetizados QDs de $\mathrm{ZnO}$ tipo- $n$ via dispersão coloidal para a fabricação de FETs, no qual a camada de QDs foi depositada por spin-coating com tratamento térmico em temperaturas que variavam de 400$600{ }^{\circ} \mathrm{C}$ com o intuito de remover as moléculas orgânicas oriundas da síntese e aumentar a sua homogeneidade. Concluíram que a camada de QD de $\mathrm{ZnO}$ ficou altamente transparente, sendo que a estrutura do dispositivo: QD $\mathrm{ZnO} / \mathrm{SiN}_{\mathrm{x}} / \mathrm{ITO} / \mathrm{Vidro}$ apresentou uma transmitância de aproximadamente $85 \%$. O transistor cuja camada de $\mathrm{ZnO}$ sofreu tratamento térmico de $600{ }^{\circ} \mathrm{C}$ apresentou os melhores desempenhos elétricos, visto que, com a eliminação das moléculas orgânicas e melhor conectividade entre partículas, proporcionou uma melhor via para a condução dos portadores de cargas ao longo do canal. Neste dispositivo, a camada de ITO atuou como eletrodo de porta e alumínio como eletrodos de fonte e dreno evaporados sobre a estrutura $\mathrm{ZnO} / \mathrm{SiN}_{\mathrm{x}} / \mathrm{ITO} /$ Vidro, numa geometria bottom-gate, top-contact.

Em 2013, Douglas Barlage e sua equipe, ${ }^{133}$ ao estudarem transistores de filme fino (TFT, do inglês Thin Film Transistors) de barreira Schottky utilizando filmes finos de $\mathrm{ZnO}$ policristalino depositados com laser pulsado à temperatura ambiente, concluíram que as respostas elétricas dos dispositivos, como por exemplo a mobilidade eletrônica de 3,9 $\mathrm{cm}^{2} \mathrm{~V}^{-1} \mathrm{~s}^{-1}$, foi compatível com outros valores da literatura para TFTs de $\mathrm{ZnO}$ à baixa temperatura. ${ }^{134,135}$

\section{USO DE QDS COMO MARCADORES BIOLÓGICOS}

Como já mencionado, os QDs têm se destacado pelas propriedades fotofísicas inigualáveis, tais como a capacidade de se ajustar o band gap, fácil obtenção através de métodos em solução e a capacidade de funcionalização de superfície. ${ }^{136,137}$ Essa última propriedade, aliada ao fato de o $\mathrm{ZnO}$ ser biocompatível, abre inúmeras possibilidades para o planejamento de sistemas com capacidade para identificar biomoléculas e outras espécies químicas, os biossensores ${ }^{138}$ e quimiossensores, ${ }^{136}$ respectivamente.

A fluorescência dos QDs é uma ferramenta de extrema relevância para se obter bons resultados de sensibilidade e seletividade na atividade do sensor, ${ }^{137}$ sendo uma resposta que traduz as propriedades biológicas ou a composição do meio em sinal óptico. ${ }^{138}$ Além disso, os QDs, comparados às moléculas orgânicas, apresentam vantagens importantes para o planejamento de marcadores biológicos, dentre elas: grande deslocamento de Stokes, permitindo que a detecção seja alcançada com sinal de baixa intensidade, região extensa de excitação e uma faixa relativamente estreita de emissão, alta estabilidade, resistência ao fenômeno de fotodegradação ou intermitência da fluorescência, tempo de vida de fluorescência longo e biocompatibilidade, que pode ser atingida diante da funcionalização da superfície ou com o uso direto de QDs não-tóxicos. ${ }^{139}$ Nesse sentido, a superfície dos QDs atua como receptora para sistemas conjugados com biomoléculas e a resposta óptica consiste em um resultado que serve para monitorar eventos que ocorrem na superfície. ${ }^{140}$

A Figura 7 representa um QD conjugado com biomoléculas, que podem ser conectadas com anticorpos, para que haja uma interação com determinados antígenos. Assim, o sistema pode ser liberado, de forma controlada, em determinados sítios ou órgãos que se deseja monitorar, devido aos primeiros sinais de um sítio ou tecido doente, por exemplo. O monitoramento se dá através de pontos luminescentes em regiões marcadas pela presença dos antígenos, dada a especificidade e a complementaridade do sistema..$^{14,140,141}$ Alternativamente, a superfície do QD pode ser revestida ou funcionalizada diretamente com os anticorpos para a detecção de proteínas ou ácidos nucleicos. ${ }^{140}$

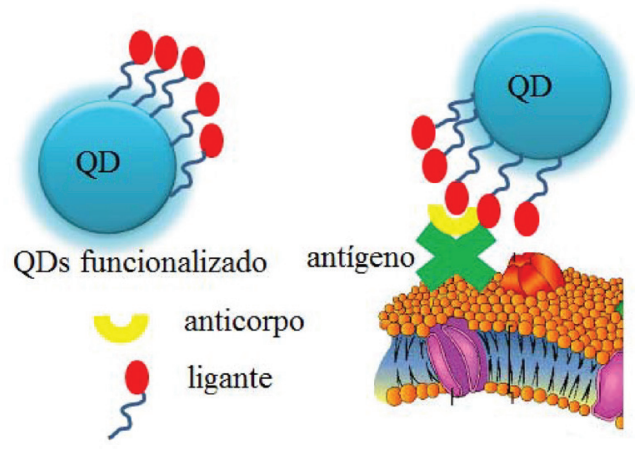

Figura 7. Representação genérica de um sistema que atua como marcador biológico a partir de uma unidade sinalizadora óptica com QD. Adaptado da ref. 14

QDs de $\mathrm{ZnO}$ desprovidos de agentes estabilizantes na superfície são instáveis. Nesse sentido, Chu e colaboradores ${ }^{142}$ propuseram um sistema para detecção de DNA, partindo inicialmente da combinação do $\mathrm{ZnO}$ com óxido de grafeno esfoliado (EGO) como sonda fluorescente para capturar ssDNA (DNA de fita simples, do inglês single-stranded DNA). A estrutura complementar do ssDNA foi identificada na superfície de NPs de prata. A hibridização das NPs metálicas, as estruturas de DNA, mais ZnO-EGO levou a uma resposta óptica de fluorescência do $\mathrm{ZnO}$ bem superior, dado o efeito da ressonância plasmônica de superfície das NPs de prata. Muitos sistemas de QDs apresentam funcionalização da superfície com ácidos carboxílicos ${ }^{143}$ ou álcool polivinílico, ${ }^{144}$ apresentando biocompatibilidade para a detecção de DNA ou monitoramento de outras biomoléculas.

A compreensão do mecanismo do desenvolvimento de infecções virais, a partir do nível viral unitário, é um grande desafio. Lv e colaboradores ${ }^{141}$ desenvolveram uma estratégia usando QDs para a identificação/marcação de envelopes virais. O método baseia-se no fato de que os lipídios biotinilados se auto inserem nas membranas celulares de células hospedeiras durante cultura e posterior propagação. O conjugado viral biotinilado foi mapeado com o uso de QDs recobertos com a estreptavidina. A proposta serviu para mostrar o mecanismo de desenvolvimento de viroses a partir de um único vírus. A investigação foi através do sinal de fluorescência, uma vez que a interação do PrV (Pseudorabies virus) com o QD-estreptavidina, manteve, sem deslocamento, a banda de emissão de fluorescência do sistema original.

Monitorar e identificar células tumorais circulantes no sistema sanguíneo é de suma importância para garantir o diagnóstico precoce. Nesse viés, Chen e colaboradores ${ }^{145}$ avaliaram a captura de células tumorais heterogêneas em substratos de hidroxiapatita-quitosana funcionalizados com estreptavidina e, seguidamente, biotinilados. Os substratos foram tratados com três anticorpos para três tipos diferentes de células tumorais. Cada célula tumoral pôde ser marcada por uma combinação QD-antígeno pela emissão de cor, para um tamanho 
específico do QD, diante da análise de imagens multiespectrais com detecção múltipla simultânea.

QDs de $\mathrm{Ag}_{2} \mathrm{~S}$ têm se mostrado muito interessantes como sondas fluorescentes com emissão na segunda janela do infravermelho próximo (NIR II - 1,0-1,4 $\mu \mathrm{m}$ ), com comprimento de onda de emissão na faixa de $1200 \mathrm{~nm}$. Esta propriedade torna-se relevante para estudos in vivo e in vitro, para detecção de tumores em estágio inicial, por exemplo. A vantagem de se obter imagens de fluorescência na região NIR II reside no fato de apresentar um efeito de espalhamento de fóton (causado pela autofluorescência dos tecidos) menor que àquelas obtidas por sondas fluorescentes na região NIR I. ${ }^{146}$

A ideia do uso dos QDs como marcadores também foi explorada por D'Amico e colaboradores ${ }^{147}$ como um conceito para avaliar a adesão de células de bovinos, denominadas condrócitos, em substratos de hidrogéis com diferentes quantidades de peptídeos RGD (sequência de reconhecimento que aumenta a tendência das células aderirem em diversas superfícies). ${ }^{148}$ Os QDs de CdSe-CdS (core-shell), recobertos com sílica, foram introduzidos nos condrócitos. A incorporação dos QDs foi eficiente e permitiu que se estudasse, via imagens de microscopia com fluorescência, os efeitos de adesão celular em substratos de hidrogéis. Esse estudo é um bom exemplo para ilustrar que a incorporação de QDs no meio celular pode acontecer, sem que estes estejam funcionalizados por moléculas orgânicas, desde que recobertos por material biocompatível. ${ }^{149}$ Além disso, o trabalho explorou o conceito de que é possível utilizar QDs na caracterização de materiais, na obtenção de informações e no monitoramento a respeito das condições do microambiente. ${ }^{147}$

De maneira geral, pode-se reconhecer os grandes avanços na área das ciências biomédicas com o uso de QDs como marcadores biológicos. ${ }^{140,150}$ Apesar das pesquisas encontrarem-se em estágio muito inicial, já é possível vislumbrar importantes contribuições no reconhecimento de moléculas-alvo, responsáveis por disfunções/ doenças, e por desvendar os mecanismos complexos de propagação no meio celular. ${ }^{139,141}$

\section{USO DE QDS COMO QUIMIOSSENSORES}

O uso de QDs como quimiossensores também está em ascensão. O planejamento dos sistemas aproveitam, principalmente, a propriedade da emissão de fluorescência dos QDs na região visível. As estratégias baseiam-se nos efeitos de superfície ${ }^{151,152}$ e na capacidade de funcionalização que estas nanoestruturas apresentam. ${ }^{153}$

Singh et al. ${ }^{152}$ exploraram o uso de QDs de $\mathrm{ZnO}$ estabilizados com 3-aminopropiltrietoxissilano na detecção do ácido pícrico em meio aquoso. O sistema se mostrou muito sensível e seletivo com um limite de detecção de $2,86 \times 10^{-6} \mathrm{~mol} \mathrm{~L}^{-1}$. O monitoramento quantitativo do ácido pícrico pôde ser feito pela supressão da fluorescência do $\mathrm{ZnO}$, na região do amarelo, diante de adições crescentes da espécie a ser detectada. A eficiência do sensor é devida a um efeito de superfície, pelo fato de o analito aprisionar os elétrons excitados na estrutura do nanocristal, por um mecanismo de transferência eletrônica.

Mahjoub et al. ${ }^{151}$ apresentaram uma metodologia para preparar NPs de ZnO e QDs ZnO@ $\mathrm{SiO}_{2}$ em metanol e, no estágio final, as nanoestruturas foram dispersas em água. O tamanho dos QDs preparados variou de 2,7-5,0 nm, distribuídos em uma matriz de $\mathrm{SiO}_{2}$. O sensor de umidade foi desenvolvido com o depósito das NPs de $\mathrm{ZnO}$ e QDs $\mathrm{ZnO} @ \mathrm{SiO}_{2}$ em um substrato de vidro, contendo dois eletrodos de ouro. A operacionalidade do sensor foi desenhada para uma corrente alternada de $1 \mathrm{~V}$, com melhor desempenho a uma frequência baixa de $40 \mathrm{~Hz}$. A umidade relativa do ar pôde ser monitorada na faixa de 5-98\% através da condutância em função do tempo. Os QDs ZnO@ $\mathrm{SiO}_{2}$ apresentaram resultados melhores, comparados com as NPs de $\mathrm{ZnO}$, devido à porosidade da sílica e pela modificação da superfície do
$\mathrm{ZnO}$, cujas ligações $\mathrm{Zn}-\mathrm{O}-\mathrm{Si}$ aumentaram a capacidade de dissociação da água pela adsorção de íons $\mathrm{HO}^{-}$e a liberação de $\mathrm{H}^{+}$.

Outra aplicação dos QDs também tem sido para a detecção de ânions e cátions, ${ }^{136}$ sendo que a maioria dos trabalhos reportados na literatura usam QDs de cádmio. ${ }^{33,136,154,155}$ As estratégias desenvolvidas têm sido baseadas na resposta óptica, diante da interação do analito iônico e a superfíce/ligantes do QD, ou ainda, através da transferência de energia por ressonância de Förster (FRET, do inglês Förster resonance energy transfer). No primeiro caso, os analitos interagem com a superfície, podendo causar a passivação dos estados de armadilha, aumentado, dessa forma, o sinal de fluorescência. Por outro lado, a interação do analito com os ligantes dos QDs, ou mesmo com os estados de superfície, pode produzir, como resultado óptico, a supressão da fluorescência. No segundo, entretanto, o ajuste do mecanismo é obtido pela combinação do analito, que pode ser com a superfície do QD ou com a molécula aceitadora de elétrons, gerando como resposta o aumento ou a supressão da fluorescência. ${ }^{136}$

Para ilustrar a detecção de íons usando QDs de ZnO, Singh e Mehta $^{156}$ apresentaram uma estratégia para a detecção de cloro livre em água de torneira. O sensor foi planejado através da resposta óptica da fluorescência diante da adição de hipoclorito. Com o aumento de hipoclorito no sistema ocorre supressão da emissão da fluorescência do $\mathrm{ZnO}$ em $525 \mathrm{~nm}$, mas nenhuma alteração ocorre na banda de absorção na região do UV. A banda de emissão em 525 nm é atribuída às vacâncias de oxigênio na estrutura cristalina. A supressão da emissão é atribuída ao processo de redução dos íons hipoclorito a cloreto pelo ganho de elétrons que estão em um estado excitado nas vacâncias de oxigênio dos QDs de ZnO. A estratégia é muito eficiente pela capacidade oxidativa que os íons hipoclorito apresentam, por isso, a seletividade foi atingida diante de vários íons testados (zinco, cobre, mercúrio, magnésio, potássio, ferro (III), sódio, sulfato, fosfato). O sensor se mostrou eficiente na faixa de $\mathrm{pH}$ da água natural de 4,0 a 10, com um limite de detecção de $4,1 \times 10^{8} \mathrm{~mol} \mathrm{~L}^{-1}$.

$\mathrm{O}$ sistema de QDs de $\mathrm{ZnO}$ revestidos com $\beta$-ciclodextrina mostrou-se eficiente para a detecção do $p$-nitrofenol. A faixa de detecção foi de $1-40 \times 10^{-6} \mathrm{~mol} \mathrm{~L}^{-1} \mathrm{com}$ um limite de detecção de $3,4 \times 10^{-7} \mathrm{~mol}$ $\mathrm{L}^{-1}$ do analito em amostras reais de água. $\mathrm{O}$ ensaio de detecção seletiva para o $p$-nitrofenol, diante de vários compostos nitrofenólicos e aromáticos, se justifica pela formação de um complexo de inclusão do analito seletivo com a $\beta$-ciclodextrina e a transferência eletrônica. O estudo quantitativo foi feito pela supressão da fluorescência diante de adições crescentes do $p$-nitrofenol. ${ }^{157}$

Outra aplicação como sensor do $\mathrm{ZnO}$ tem sido na detecção de gases. O monitoramento quantitativo do gás sulfídrico é de extrema relevância, por ser uma substância altamente tóxica, incolor e inflamável. Filmes de QDs de $\mathrm{ZnO}$ em substratos de alumina foram preparados quimicamente, via rota úmida, para a avaliação do potencial do sistema como sensor para o $\mathrm{H}_{2} \mathrm{~S} .{ }^{158} \mathrm{~A}$ ideia da estratégia está baseada na resposta de condutividade. Os filmes mostraram-se mais eficientes quando tratados termicamente a $300{ }^{\circ} \mathrm{C}$, elevando o tamanho dos cristais, mas propiciando o desenvolvimento de estruturas alongadas que melhoraram a condutividade do filme. $\mathrm{O}$ sensor foi seletivo diante de $\mathrm{NO}_{2}, \mathrm{SO}_{2}$ e $\mathrm{NH}_{3}$.

\section{USO DE QDS COMO BLOQUEADORES DE UV E FOTOCATALISADORES}

A combinação de materiais orgânicos e inorgânicos tem propiciado o surgimento de uma classe de novos materiais com propriedades melhoradas, distintas daquelas dos componentes individuais. Uma demanda crescente é o desenvolvimento de materiais fotoprotetores, dada a incidência crescente de radiação UV na Terra, consequência das alterações atmosféricas. ${ }^{159}$ Nessa perspectiva, a criação de 
materiais transparentes que tenham atividade bloqueadora de radiação UV se torna relevante. Polímeros e nanoestruturas inorgânicas, como materiais híbridos, têm sido usados para essa finalidade.

O preparo de compósitos ou híbridos, de polímeros e nanoestruturas inorgânicas, que apresentem transparência e homogeneidade é desafiante. As dificuldades que permeiam a produção de híbridos transparentes e homogêneos são devido às diferenças nos índices de refração, provocando o espalhamento da luz e, consequentemente, a opacidade. Além disso, as diferenças de polaridade das fases polimérica e daquela do material inorgânico levam à separação das fases. ${ }^{159} \mathrm{Li}$ e colaboradores ${ }^{159}$ apresentaram a síntese de um híbrido transparente PMMA-ZnO com capacidade de bloquear os raios UV a partir de concentrações muita baixas de QDs de $\mathrm{ZnO}$ (0,017\% em massa) na matriz polimérica. A obtenção de filmes homogêneos e transparentes foi possível pela adição da monoetanolamina (MEA) como agente complexante e de acoplamento de fases. Nesse sentido, a MEA foi adicionada com o precursor acetato de zinco di-hidratado, para levar à formação das nanoestruturas de $\mathrm{ZnO}$, inibindo a aglomeração e atuando também no acoplamento das fases de polaridades distintas, pela capacidade da MEA de funcionalizar ambos, o polímero e o $\mathrm{ZnO}$, através dos grupos hidroxilas. A reação de polimerização a partir do metil-metacrilato ocorreu nesse mesmo meio reacional de formação das nanoestruturas.

O fator de proteção UV em tecidos também tem sido uma preocupação na área de melhoramento de materiais. Um estudo de tratamento de algodão com uma dispersão de QDs de ZnO levou à obtenção de um tecido com uma excelente propriedade bloqueadora de UV, com um UPF (do inglês, Ultraviolet Protection Factor) extremamente alto, com um valor de 118,12 . A metodologia apresentada foi por imersão do tecido, previamente tratado, nas dispersões de QDs e soluções de acetato e nitrato de zinco para a obtenção e crescimento de $\mathrm{ZnO}$ na forma de nanoflores e nanobastões. As medidas ópticas do tecido tratado com as estruturas cristalinas de $\mathrm{ZnO}$ apresentaram variações drásticas no efeito de blindagem da radiação na região de 200-360 nm. ${ }^{160}$

Eita e colaboradores ${ }^{161}$ exploraram a flexibilidade do polidimetilsiloxano (PDMS), característica que o diferencia do PMMA, para formar uma material flexível e transparente que absorve na região do UV, diante da incorporação de QDs de ZnO. O material híbrido foi formado por bicamadas, iniciado com PDMS e finalizado com QDs de $\mathrm{ZnO}$, através da técnica de spin coating. Quanto maior o número de bicamadas, maior foi o efeito de absorção na região do UV.

A aplicação de nanoestruturas semicondutoras, tais como o $\mathrm{TiO}_{2} \mathrm{e}$ $\mathrm{ZnO}$, em fotocatálise é devido a capacidade das partículas em absorver a energia UV e transformar em energia química. Dentre as reações fotocatalíticas, estão aquelas capazes de promover a degradação de compostos potencialmente tóxicos, gerando uma tecnologia que pode ser aplicável em processos de tratamentos de efluentes, oxidação seletiva, descontaminação do ar e destruição de poluentes de maneira geral. ${ }^{162}$ Além disso, o uso de semicondutores para converter energia solar em hidrogênio, via fotocatálise, aparece como uma atividade de muito apelo científico. ${ }^{163}$

As reações fotocatalíticas para semicondutores ocorrem após a ativação das partículas pela absorção da radiação UV. Os fótons absorvidos, com energia superior ou igual a energia do band gap, fazem com que os elétrons da BV migrem para a BC gerando um par elétron-buraco. ${ }^{164}$ As reações fotocatalíticas passam por um mecanismo que envolve a produção de espécies reativas de oxigênio, diante da absorção da radiação UV, gerando espécies altamente oxidantes, citotóxicas e genotóxicas. Dessa forma, a atividade fotocatalisadora de espécies como o $\mathrm{ZnO}$ pode não ser desejada, quando esse for um componente de cremes ou loções de proteção solar. ${ }^{165}$ Nessa perspectiva, Regiel-Futyra e colaboradores ${ }^{165}$ apresentaram um híbrido entre o $\mathrm{ZnO}$ e o biopolímero quitosana, formado por gelificação ionotrópica, que manteve as propriedades protetoras da radiação UV, ao mesmo tempo que teve sua atividade fotocatalisadora suprimida, pelo efeito da quitosana.

A literatura relata a ação fotocatalítica do dióxido de titânio, especialmente para a degradação de poluentes orgânicos, como sendo o único aplicado em processos industriais. ${ }^{166} \mathrm{~A}$ superfície de $\mathrm{TiO}_{2}$ acomoda sítios de oxidação e redução. O oxigênio molecular se reduz à forma $\mathrm{O}_{2}{ }^{-}$, desencadeando a formação de espécies radicalares. Os buracos, gerados pela absorção dos fótons, são altamente oxidantes, levando a maioria dos compostos orgânicos à sua forma completa de oxidação, pela liberação de $\mathrm{CO}_{2}$. A Figura 8 ilustra a atividade de um fotocatalisador na degradação de compostos orgânicos. Observou-se que a combinação de uma superfície de carbono amorfo melhorou a atividade fotocatalítica devido ao fenômeno de adsorção do composto orgânico a ser degradado. ${ }^{167}$

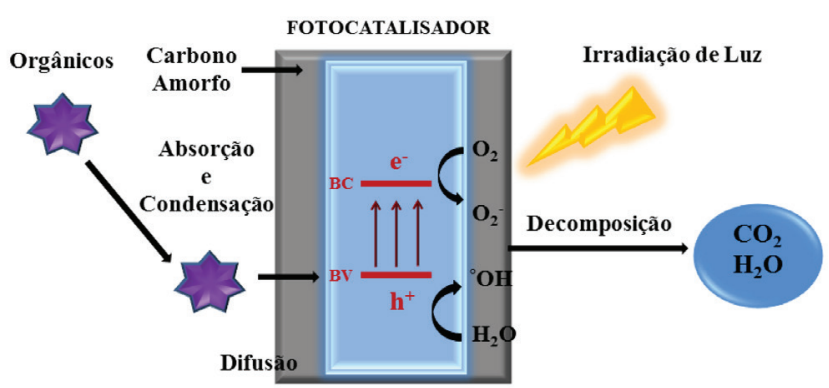

Figura 8. Mecanismo proposto para fotocatálisedenanoestruturas C@ZnO. Adaptado da ref. 167, com permissão da Elsevier

Os óxidos metálicos semicondutores, tais como $\mathrm{TiO}_{2}$ e $\mathrm{ZnO}$, ainda apresentam muitas limitações na atividade fotocatalítica a partir da energia solar, por apresentarem um band gap elevado. Daí a importância de se trabalhar com sistemas híbridos e com modificações dos estados energéticos de superfície, via dopagem ou criando-se defeitos e estados de desordem. Nessas circunstâncias, pela adição de potássio, foi possível atingir condições significativamente melhoradas, com um efeito catalítico 300 vezes maior que o correspondente material de $\mathrm{TiO}_{2}$ e $\mathrm{ZnO}$, sem potássio. ${ }^{168}$

Tao e colaboradores ${ }^{169}$ investigaram a atividade fotocatalítica de um sistema híbrido de $\mathrm{Ag} / \mathrm{TiO}_{2} / \mathrm{ZnO}$, sendo a prata na forma de QD. A velocidade de degradação do alaranjado de metila aumentou em $109 \%$, comparado com o $\mathrm{TiO}_{2}$. Esse resultado foi explicado pelo aumento do efeito da separação de cargas (elétrons e buracos), diante da adição do $\mathrm{ZnO}$ e da ressonância plasmônica de superfície da prata. Esse efeito combinado está ilustrado na Figura 9.

Dentre as nanoestruturas estudadas para a atividade fotocatalítica, QDs de natureza não tóxica se destacam pela alta eficiência da ação degradativa, como é o caso do $\mathrm{ZnO}$. Um sistema híbrido, composto por QDs de $\mathrm{ZnO}$ dispersos em uma matriz de $\mathrm{S}^{2-}$ e $\mathrm{SO}_{3}{ }^{2-}$, foi investigado para avaliação da eficiência fóton-elétron-geração de hidrogênio. A matriz aniônica esteve diretamente relacionada com a eficiência fotocatalítica de produção de hidrogênio, pois foi planejada para provocar o surgimento de buracos e defeitos superficiais. O sistema híbrido QDs de $\mathrm{ZnO} / \mathrm{S}^{2-}$ e $\mathrm{SO}_{3}{ }^{2-}$ fez aumentar a velocidade de produção de $\mathrm{H}_{2}$ em mais de 250 vezes, quando comparado com QDs de $\mathrm{ZnO} .{ }^{163}$

O sistema catalítico, composto por QDs de $\mathrm{ZnO}$ em uma estrutura macroporosa tridimensionalmente ordenada de $\mathrm{TiO}_{2}$, foi avaliado para a degradação de rodamina B. Constatou-se que a atividade fotocatalítica é fortemente dependente da quantidade de QDs de $\mathrm{ZnO}$, mostrando-se como um sistema de heterojunção bem sucedido, aumentando a eficiência da separação do par elétron-buraco e permitindo a transferência de carga interfacial, já que as posições das bandas 


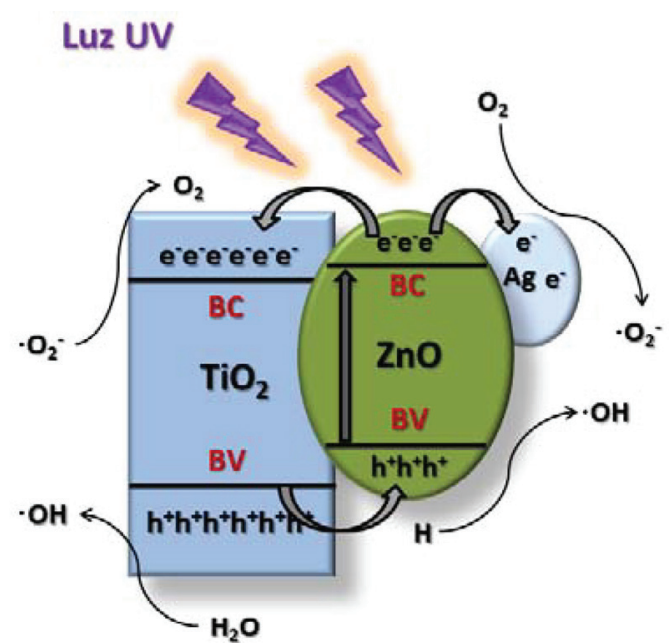

Figura 9. Mecanismo de reação com nanoestruturas de TiO2/ZnO/Ag sob radiação de luz UV Adaptado da ref. 169, com permissão da Elsevier

energéticas do $\mathrm{TiO}_{2}$ e $\mathrm{ZnO}$ favorecem uma transferência rápida. O mecanismo de degradação do corante por esse sistema está baseado no fato de que os elétrons da $\mathrm{BC}$ do $\mathrm{TiO}_{2}$ agem como redutores, levando o $\mathrm{O}_{2}$ adsorvido a $\mathrm{O}_{2}{ }^{-}$com a subsequente transformação das moléculas de água nos radicais $\mathrm{OH}^{*}$, que levam à degradação total do corante nas formas de $\mathrm{CO}_{2}$ e $\mathrm{H}_{2} \mathrm{O}$, conforme Figura 8. ${ }^{170}$

\section{CONSIDERAÇÕES FINAIS}

Os materiais semicondutores nanoestruturados, em especial os pontos quânticos, destacam-se por um conjunto de características úteis para construção de sistemas diferenciados e inteligentes, tais como: os marcadores biológicos, quimiossensores, (foto)catalisadores, bloqueadores de radiação UV, dispositivos eletrônicos, etc. Entretanto, a preocupação com os aspectos ambientais, a saúde e a segurança, suscita a busca por materiais alternativos, tidos como ambientalmente amigáveis, que atendam às demandas científicas e tecnológicas da atualidade.

Nessa perspectiva, os QDs de $\mathrm{ZnO}$, tidos como de baixa toxicidade e biocompatíveis, têm recebido especial atenção, devido as suas propriedades, principalmente as ópticas e eletrônicas. Uma melhora significativa dessas propriedades, bem como da estabilidade química, tem sido alcançada graças ao controle dos processos sintéticos e à engenharia de superfície. Como resultado, um vasto número de trabalhos tem explorado os potenciais de aplicação em sistemas biológicos, no monitoramento de células tumorais, no controle da atividade fotoprotetora em detrimento da atividade fotocatalítica, ou como fotocatalisador, sendo inclusive uma alternativa viável para a produção de gás hidrogênio a partir da água e na degradação de poluentes. Além disso, NPs de ZnO têm sido aplicadas como camada ativa e transportadora de portadores de carga em dispositivos eletrônicos como diodos emissores de luz, células solares e transístores, sendo que as peculiaridades dos QDs podem ser devidamente exploradas para otimizar e ampliar o alcance de aplicação destes dispositivos.

QDs de natureza biocompatível têm sido amplamente utilizados formando materiais híbridos ou compósitos. Uma vantagem a ser destacada é a versatilidade dos processos de síntese e compatibilidade com uma vasta gama de substratos tais como os vidros transparentes e materiais poliméricos flexíveis.

Em suma, os avanços envolvendo nanoestruturas de semicondutores não seriam possíveis sem a evolução nas estratégias de síntese, de combinações moleculares e construções supramoleculares, envolvendo materiais orgânicos e inorgânicos. Dessas combinações, advêm as tecnologias que superam os limites convencionais e têm instigado para novas investigações e promissoras aplicações.

\section{REFERÊNCIAS}

1. Mansur, H. S.; Mansur, A. A. P.; Soriano-Araujo, A.; Lobato, Z. I. P.; Green Chem. 2015, 17, 1820.

2. Ekimov, A. I.; Onushchenko, A. A.; JETP Lett. 1981, 34, 345.

3. Achermann, M.; Petruska, M. A.; Kos, S.; Smith, D. L.; Koleske, D. D.; Klimov, V. I.; Nature 2004, 429, 642.

4. Murray, C. B.; Norris, D. J.; Bawendi, M. G.; J. Am. Chem. Soc. 1993, 115,8706 .

5. Alivisatos, A. P.; Science 1996, 271, 933.

6. Huo, Y. H.; Witek, B. J.; Kumar, S.; Cardenas, J. R.; Zhang, J. X.; Akopian, N.; Singh, R.; Zallo, E.; Grifone, R.; Kriegner, D.; Trotta, R.; Ding, F.; Stangl, J.; Zwiller, V.; Bester, G.; Rastelli, A.; Schmidt, O. G.; Nat. Phys. 2014, 10, 46.

7. Boero, M.; Rorison, J. M.; Duggan, G.;Inkson, J. C.; Surf. Sci. 1997, 377,371 .

8. Scholes, G. D.;Rumbles, G.; Nat. Mater. 2006, 5, 683.

9. Brus, L. E.; Nano Lett. 2010, 10, 363.

10. Schmittrink, S.; Chemla, D. S.; Miller, D. A. B.; Adv. Phys. 1989, $38,89$.

11. Mansur, H. S.; WIREs Nanomedicine and Nanobiotechnology 2010, 2 , 113.

12. Lacroix, L.-M.; Delpech, F.; Nayral, C.; Lachaize, S.; Chaudret, B.; Interface Focus 2013, 3 .

13. Fu, Y.; Zhang, J.; Lakowicz, J. R.; Photochem. Photobiol. 2009, 85, 646.

14. Madani, S. Y.; Shabani, F.; Dwek, M. V.; Seifalian, A. M.; Int. J. Nanomed. 2013, 8, 941.

15. Yang, Y.; Zheng, Y.; Cao, W.; Titov, A.; Hyvonen, J.; MandersJesse, R.; Xue, J.; Holloway, P. H.; Qian, L.; Nat. Photon. 2015, 9, 259.

16. Wood, V.; Panzer, M.; Sullivan, S-C.; Bulovic, V. In Colloidal Quantum Dot Optoelectronics and Photovoltaics; Konstantatos, G.; Sargent, E. H., eds.; Cambridge University Press: Cambridge, 2013, cap. 6.

17. Wang, L.; Chen, T.; Lin, Q.; Shen, H.; Wang, A.; Wang, H.; Li, C.; Li, L. S.; Org. Electron. 2016, 37, 280.

18. Pietryga, J. M.; Park, Y. S.; Lim, J. H.; Fidler, A. F.; Bae, W. K.; Brovelli, S.; Klimov, V. I.; Chem. Rev. 2016, 116, 10513.

19. Kagan, C. R.; Lifshitz, E.; Sargent, E. H.; Talapin, D. V.; Science 2016, 353,885 .

20. Kloeffel, C.; Loss, D.; Ann. Rev. Condens. Matter Phys. 2013, 4, 51.

21. Cho, J. E.; Yu, J.; Kang, S. J.; Curr. Appl. Phys. 2016, 16, 1560.

22. Sargent, E. H.; Nat. Photon. 2012, 6, 133.

23. Zhitomirsky, D.; Kramer, I. J.; Labelle, A. J.; Fischer, A.; Debnath, R.; Pan, J.; Bakr, O. M.; Sargent, E. H.; Nano Lett. 2012, 12, 1007.

24. Medintz, I. L.; Uyeda, H. T.; Goldman, E. R.; Mattoussi, H.; Nat. Mater. 2005, 4, 435 .

25. Liu, X.; Luo, Y.; Chin. J. Anal. Chem. 2014, 42, 1061.

26. Kannan, R.; Kim, A. R.; Kim, J. S.; Yoo, D. J.; Int. J. Hydrog. Energy 2016, 41, 18033.

27. Liu, X. M.; Cheng, H.; Fu, F. M.; Huang, W. Y.; Zuo, H. J.; Yan, L. J.; Li, L. J.; Mater. Lett. 2016, 179, 134.

28. Han, X.; Han, Y. Z.; Huang, H.; Zhang, H. C.; Zhang, X.; Liu, R. H.; Liu, Y.; Kang, Z. H.; Dalton Trans. 2013, 42, 10380.

29. Murray, C. B.; Bawendi, M. G.; Abstracts of Papers of the American Chemical Society 1993, 205, 136.

30. Alvi, M. A.; Al-Ghamdi, A. A.; Zulfequar, M.; J. Nanoelectron. Optoelectron. 2016, 11, 656.

31. Zhou, R.; Wan, L.; Niu, H. H.; Yang, L.; Mao, X. L.; Zhang, Q. F.; Miao, S. D.; Xu, J. Z.; Cao, G. Z.; Sol. Energy Mater. Sol. Cells. 2016, 155, 20.

32. Punnoose, D.; Suh, S. M.; Kim, B. J.; Kim, S. K.; Kumar, C.; Rao, S. S.; Thulasi-Varma, C. V.; Reddy, A. E.; Chung, S. H.; Kim, H. J.; J. Electroanal. Chem. 2016, 773, 27. 
33. Gong, T. T.; Liu, J. F.; Liu, X. X.; Liu, J.; Xiang, J. K.; Wu, Y. W.; Food Chem. 2016, 213, 306.

34. Wang, H. L.; Zhu, W. J.; Fang, M.; Xu, Y.; Li, C.; J. Lumin. 2016, 180, 14.

35. Talapin, D. V.; Steckel, J.; MRS Bull. 2013, 38, 685.

36. Saha, S.; Sarkar, P.; RSC Adv. 2014, 4, 1640.

37. Ashby, M. F.; Materials and the Environment, $2^{\text {th }}$ ed., ButterworthHeinemann: Boston, 2013.

38. Uekawa, N.; Iahii, S.; Kojima, T.; Kakegawa, K.; Mater. Lett. 2007, 61, 1729.

39. Science Communication Unit, University of the West of England, Bristol. Science for Environment Policy In-depth Report: Social Innovation and the Environment, Report produced for the European Commission DG Environment, 2014.

40. Hutchison, J. E.; ACS Sustain. Chem. Eng. 2016, 4, 5907.

41. Roco, M. C.; Environ. Sci. Technol. 2005, 39, 106A.

42. Silva, F. O.; Viol, L. C. d. S.; Ferreira, D. L.; Alves , J. L. A.; Schiavon, M. A.; Quim. Nova 2010, 33, 1933.

43. Ji, W. Y.; Jing, P. T.; Fan, Y.; Zhao, J. L.; Wang, Y. J.; Kong, X. G.; Opt. Lett. 2013, 38, 7.

44. Silva, B. F.; Andreani, T.; Gavina, A.; Vieira, M. N.; Pereira, C. M.; Rocha-Santos, T.; Pereira, R.; Aquat. Toxicol. 2016, 176, 197.

45. Valipoor, A.; Parivar, K.; Modaresi, M.; Amiri, G. R.; Messripour, M.; J. Optoelectron. Adv. Mater. 2013, 7, 252.

46. Hardman, R.; Environ. Health Perspect. 2006, 114, 165.

47. Yakoubi, A.; Ben Chaabane, T.; Aboulaich, A.; Mahiou, R.; Balan, L.; Medjahdi, G.; Schneider, R.; J. Lumin. 2016, 175, 193.

48. Pleskova, S. N.; Pudovkina, E. E.; Mikheeva, E. R.; Gorshkova, E. N.; Bull. Exp. Biol. Med. 2014, 156, 384.

49. Jamieson, T.; Bakhshi, R.; Petrova, D.; Pocock, R.; Imani, M.; Seifalian, A. M.; Biomaterials 2007, 28, 4717.

50. Zhang, R.; Liu, Y. B.; Sun, S. Q.; Appl. Surf. Sci. 2013, 282, 960.

51. Yong, K. T.; Roy, I.; Pudavar, H. E.; Bergey, E. J.; Tramposch, K. M.; Swihart, M. T.; Prasad, P. N.; Adv. Mater. 2008, 20, 1412.

52. Fonoberov, V. A.; Balandin, A. A.; Appl. Phys. Lett. 2004, 85, 5971.

53. Mosquera, A. A.; Horwat, D.; Rashkovskiy, A.; Kovalev, A.; Miska, P.; Wainstein, D.; Albella, J. M.; Endrino, J. L.; Sci. Rep. 2013, 3.

54. Djurisic, A. B.; Leung, Y. H.; Small 2006, 2, 944.

55. Das, S.; Ghosh, C. K.; Dey, R.;Pal, M.; RSC Adv. 2016, 6, 236.

56. Jacobsson, T. J.; Edvinsson, T.; Inorg. Chem. 2011, 50, 9578.

57. Alivisatos, A. P.; Gu, W.;Larabell, C.; Annu. Rev. Biomed. Eng. 2005, 7, 55.

58. Liu, M.; Kitai, A. H.; Mascher, P.; J. Lumin. 1992, 54, 35.

59. Zhang, J.; Zhao, S. Q.; Zhang, K.; Zhou, J. Q.; Cai, Y. F.; Nanoscale Res. Lett. 2012, 7, 1.

60. Park, J.; Joo, J.; Kwon, S. G.; Jang, Y.; Hyeon, T.; Angew. Chem. Int. Ed. 2007, 46, 4630 .

61. Rogach, A. L.; Talapin, D. V.; Shevchenko, E. V.; Kornowski, A.; Haase, M.; Weller, H.; Adv. Funct. Mater. 2002, 12, 653.

62. Silva, F. O.; Viol, L. C. D.; Ferreira, D. L.; Alves, J. L. A.; Schiavon, M. A.; Quim. Nova 2010, 33, 1933.

63. Yang, J.; Ling, T.; Wu, W. T.; Liu, H.; Gao, M. R.; Ling, C.; Li, L.; Du, X. W.; Nat. Commun. 2013, 4.

64. Róz, A. L.; Leite, F. L.; Oliveira, J. M. F. O. N. Nanoestruturas: Princípios e Aplicações, $1^{\text {th }}$ ed., Elsevier: Rio de Janeiro, 2015.

65. Bera, D.; Qian, L.; Tseng, T. K.;Holloway, P. H.; Materials 2010, 3, 2260 .

66. Pan, S. S.; Lu, W.; Chu, Z. Q.; Li, G. H.; J. Mater. Sci. Technol. 2015, 31,670 .

67. Lee, L. K.; Ku, P. C.; Phys. Status Solidi C 2012, 9, 609.

68. Luo, X. B.; Guo, B.; Wang, L. C.; Deng, F.; Qi, R. X.; Luo, S. L.; Au, C. T.; Colloids Surf., A 2014, 462, 186.

69. Peng, S. S.; Zhang, X. L.; Microchim. Acta 2012, 178, 323.
70. Lan, Y. W.; Yang, K.; Wang, Y. L.; Li, H. M.; Micro Nano Lett. 2014, 9, 202.

71. Zhang, J.; Li, S. L.; Xiong, H.; Tian, W.; Li, Y.; Fang, Y. Y.; Wu, Z. H.; Dai, J. N.; Xu, J. T.; Li, X. Y.; Chen, C. Q.; Nanoscale Res. Lett. 2014, 9 .

72. Bu, H. B.; Watanabe, T.; Hizume, M.; Takagi, T.; Sobue, S.; Kawai, S.; Okuno, E.; Kim, D.; Mater. Res. Express. 2015, 2.

73. Sun, H. S.; Xing, Y. G.; Wu, Q. A.; Yang, P.; J. Nanosci. Nanotechnol. 2015, 15, 1562

74. Choi, M. S.; Meshik, X.; Mukherjee, S.; Farid, S.; Doan, S.; Covnot, L.; Dutta, M.; Stroscio, M. A.; J. Appl. Phys. 2015, 118.

75. Zeng, H. B.; Yang, S. K.; Cai, W. P.; J. Phys. Chem C 2011, 115, 5038.

76. Lu, J. G.; Ye, Z. Z.; Zhang, Y. Z.; Liang, Q. L.; Fujita, S.; Wang, Z. L.; Appl. Phys. Lett. 2006, 89.

77. Kim, S. W.; Fujita, S.; Fujita, S.; Appl. Phys. Lett. 2002, 81, 5036.

78. Du, Y. Y.; Yang, P.; Matras-Postolek, K.; Wang, J. P.; Che, Q. D.; Cao, Y. Q.; Ma, Q.; J Nanopart. Res. 2016, 18.

79. Xu, X. M.; Wang, Y. L.; Gule, T.; Luo, Q.; Zhou, L. Y.; Gong, F. Z.; Mater. Res. Bull. 2013, 48, 983.

80. Asok, A.; Kulkarni, A. R.; Gandhi, M. N.; Pure Appl. Chem. 2015, 87, 971.

81. Schneider, R.; Balan, L.; Aldeek, F.; In Nanomaterials; Rahman, M., ed.; InTech, 2011, DOI: 10.5772/27238.

82. Hiratsuka, R. S.; Santilli, C. V.; Pulsinelli, S. H.; Quim. Nova 1995, 18, 171.

83. Brinker, C. J.; Scherer, G. W. Sol-Gel Science, Academic Press: San Diego, 1990.

84. He, R. L.; Tsuzuki, T.; J. Am. Ceram. Soc. 2010, 93, 2281.

85. Rahman, M. M. Nanomaterials, $1^{\mathrm{a}}$ ed., Rijeka, 2011.

86. Patra, M. K.; Manoth, M.; Singh, V. K.; Gowd, G. S.; Choudhry, V. S.; Vadera, S. R.; Kumar, N.; J. Lumin. 2009, 129, 320.

87. Yang, W. M.; Zhang, B.; Ding, N.; Ding, W. H.; Wang, L. X.; Yu, M. X.; Zhang, Q. T.; Ultrason. Sonochem. 2016, 30, 103.

88. Alias, S. S.; Ismail, A. B.; Mohamad, A. A.; J. Alloy Compd. 2010, 499, 231.

89. Meulenkamp, E. A.; J. Phys. Chem. B 1998, 102, 5566.

90. Qiao, B.; Zhao, S.; Xu, Z.; Xu, X.; Chin. Phys. B 2016, 25, 098102.

91. Hale, P. S.; Maddox, L. M.; Shapter, J. G.; Voelcker, N. H.; Ford, M. J.; Waclawik, E. R.; J. Chem. Educ. 2005, 82, 775.

92. Daneshvar, N.; Aber, S.; Dorraji, M. S.; Khataee, A.; Rasoulifard, M.; Sep. Purif. Technol. 2007, 58, 91

93. Lee, S.; Jeong, S.; Kim, D.; Hwang, S.; Jeon, M.; Moon, J.; Superlattices Microstruct. 2008, 43, 330.

94. Schejn, A.; Frégnaux, M.; Commenge, J.-M.; Balan, L.; Falk, L.; Schneider, R.; Nanotechnology 2014, 25, 145606.

95. Pinna, N.; Niederberger, M.; Angew. Chem., Int. Ed. 2008, 47, 5292.

96. Xiong, H.-M.; Ma, R.-Z.; Wang, S.-F.; Xia, Y.-Y.; J. Mater. Chem. 2011, 21,3178 .

97. Kunjara Na Ayudhya, S.; Tonto, P.; Mekasuwandumrong, O.; Pavarajarn, V.; Praserthdam, P.; Cryst. Growth Des. 2006, 6, 2446.

98. Zhang, Y.; Nayak, T. R.; Hong, H.; Cai, W.; Curr. Mol. Med. 2013, 13, 1633.

99. Fu, Y. S.; Du, X. W.; Kulinich, S. A.; Qiu, J. S.; Qin, W. J.; Li, R.; Sun, J.; Liu, J.; J. Am. Chem. Soc. 2007, 129, 16029.

100. Sirringhaus, H.; Adv. Mater. 2005, 17, 2411.

101. Ruiz, C.; García-Frutos, E. M.; Hennrich, G.; Gómez-Lor, B.; J. Phys. Chem. Lett. 2012, 3, 1428.

102. Facchetti, A.; Nat. Mater. 2013, 12, 598

103. Passo, J. A.; Merlo, A. A.; Eccher, J.; Bechtold, I. H.; Kelly, S. M.; Quim. Nova 2012, 35, 1527.

104. Eccher, J.; Zajaczkowski, W.; Faria, G. C.; Bock, H.; von Seggern, H.; Pisula, W.; Bechtold, I. H.; ACS Appl. Mater. Interfaces 2015, 7, 16374.

105. Bechtold, I. H.; Rev. Bras. Ensino Fis. 2005, 27, 333. 
106. Bushby, R. J.; Boden, N. Handbook of Liquid Crystals: vol. 3, WileyVCH Verlag Gmbh \& Co. Kgaa: Weinheim, 2014.

107. Wöhrle, T.; Wurzbach, I.; Kirres, J.; Kostidou, A.; Kapernaum, N.; Litterscheidt, J.; Haenle, J. C.; Staffeld, P.; Baro, A.; Giesselmann, F.; Laschat, S.; Chem. Rev. 2016, 116, 1139.

108. Liu, S.; Liu, W.; Ji, W.; Yu, J.; Zhang, W.; Zhang, L.; Xie, W.; Sci. Rep. 2016, 6, 22530.

109. Bai, Z.; Ji, W.; Han, D.; Chen, L.; Chen, B.; Shen, H.; Zou, B.; Zhong, H.; Chem. Mater. 2016, 28, 1085.

110. Qian, L.; Zheng, Y.; Xue, J.; Holloway, P. H.; Nat. Photon. 2011, 5, 543.

111. Thiyagarajan, P.; Kottaisamy, M.; Rama, N.; Ramachandra Rao, M. S.; Scripta Materialia 2008, 59, 722.

112. Dong Ick, S.; Chan Ho, Y.; Won Tae, K.; Tae Whan, K.; Nanotechnology 2009, 20, 365206.

113. Chen, J.; Zhao, D.; Li, C.; Xu, F.; Lei, W.; Sun, L.; Nathan, A.; Sun, X. W.; Sci. Rep. 2014, 4, 4085.

114. Yang, Z.; Voznyy, O.; Liu, M.; Yuan, M.; Ip, A. H.; Ahmed, O. S.; Levina, L.; Kinge, S.; Hoogland, S.; Sargent, E. H.; ACS Nano 2015, 9, 12327.

115. Kouhnavard, M.; Ikeda, S.; Ludin, N. A.; Ahmad Khairudin, N. B.; Ghaffari, B. V.; Mat-Teridi, M. A.; Ibrahim, M. A.; Sepeai, S.; Sopian, K.; Renewable Sustainable Energy Rev. 2014, 37, 397.

116. Li, Q.; Jin, X.; Yang, Y.; Wang, H.; Xu, H.; Cheng, Y.; Wei, T.; Qin, Y.; Luo, X.; Sun, W.; Luo, S.; Adv. Funct. Mater. 2016, 26, 254.

117. Kagan, C. R.; Lifshitz, E.; Sargent, E. H.; Talapin, D. V.; Science 2016, 353.

118. Hoye, R. L. Z.; Ehrler, B.; Böhm, M. L.; Muñoz-Rojas, D.; Altamimi, R. M.; Alyamani, A. Y.; Vaynzof, Y.; Sadhanala, A.; Ercolano, G.; Greenham, N. C.; Friend, R. H.; MacManus-Driscoll, J. L.; Musselman, K. P.; Adv. Energy Mat. 2014, 4, 1301544.

119. Wu, F.; Zhao, Y.; Zhang, H.; Tong, Y.; Appl. Phys. A 2015, 120, 941.

120. Choi, M.-J.; Kim, S.; Lim, H.; Choi, J.; Sim, D. M.; Yim, S.; Ahn, B. T.; Kim, J. Y.; Jung, Y. S.; Adv. Mater. 2016, 28, 1780.

121. Zhang, Q.; Dandeneau, C. S.; Zhou, X.; Cao, G.; Adv. Mater. 2009, 21, 4087.

122. Bu, I. Y. Y.; Ceram. Int. 2013, 39, 8073.

123. Zazueta-Raynaud, A.; Pelayo-Ceja, J. E.; Lopez-Delgado, R.; Ayon, A.; J. Phys. Conf. Ser. 2016, 773, 012036.

124. Vitoreti, A. B. F.; Corrêa, L. B.; Raphael, E.; Patrocinio, A. O. T.; Nogueira, A. F.; Schiavon, M. A.; Quim. Nova 2017, 40, 436.

125. Lan, X.; Masala, S.; Sargent, E. H.; Nat. Mater. 2014, 13, 233.

126. Tang, J.; Liu, H.; Zhitomirsky, D.; Hoogland, S.; Wang, X.; Furukawa, M.; Levina, L.; Sargent, E. H.; Nano Letters 2012, 12, 4889.

127. Hetsch, F.; Zhao, N.; Kershaw, S. V.; Rogach, A. L.; Mater. Today 2013, 16,312 .

128. Shulga, A. G.; Piveteau, L.; Bisri, S. Z.; Kovalenko, M. V.; Loi, M. A.; Adv. Electron Mater. 2016, 2, 1500467.

129. Zhang, Y.; Chen, Q.; Alivisatos, A. P.; Salmeron, M.; Nano Letters 2015, $15,4657$.

130. Hirao, T.; Furuta, M.; Hiramatsu, T.; Matsuda, T.; Li, C.; Furuta, H.; Hokari, H.; Yoshida, M.; Ishii, H.; Kakegawa, M.; IEEE Trans. Electron Devices 2008, 55, 3136.

131. Brox-Nilsen, C.; Jin, J.; Luo, Y.; Bao, P.; Song, A. M.; IEEE Trans. Electron Devices 2013, 60, 3424.

132. Joo-Seob, A.; Jong-Jin, L.; Gun Woo, H.; Young Kwan, K.; Heesun, Y.; J. Phys. D: Appl. Phys. 2010, 43, 275102.

133. Ma, A. M.; Gupta, M.; Afshar, A.; Shoute, G.; Tsui, Y. Y.; Cadien, K. C.; Barlage, D. W.; Appl. Phys. Lett. 2013, 103, 253503.

134. Grundbacher, R.; Chikkadi, K.; Hierold, C.; J. Vac. Sci. Technol., B: Nanotechnol. Microelectron.: Mater., Process., Meas., Phenom. 2010, $28,1173$.

135. Semyung, K.; Seokhwan, B.; Seungjun, L.; Sunyeol, J.; Wooho, J.; Hyungchul, K.; Su Cheol, G.; Ho Jung, C.; Hyung-Ho, P.; Hyeongtag, J.; Semicond. Sci. Technol. 2009, 24, 035015.
136. Lou, Y.; Zhao, Y.; Zhu, J.-J.; Nanoscale Horizons 2016, 1, 125.

137. Frasco, M.; Chaniotakis, N.; Sensors 2009, 9, 7266.

138. Xu, C.; Yang, C.; Gu, B.; Fang, S.; Chin. Sci. Bull. 2013, 58, 2563.

139. Zhao, M.-X.; Zeng, E.-Z.; Nanoscale Res. Lett. 2015, 10, 171.

140. Gill, R.; Zayats, M.; Willner, I.; Angew. Chem., Int. Ed. 2008, 47, 7602.

141. Lv, C.; Lin, Y.; Liu, A.-A.; Hong, Z.-Y.; Wen, L.; Zhang, Z.; Zhang, Z.-

L.; Wang, H.; Pang, D.-W.; Biomaterials 2016, 106, 69.

142. Chu, C. C.; Shen, L.; Ge, S. G.; Ge, L.; Yu, J. H.; Yan, M.; Song, X. R.; Biosens. Bioelectron. 2014, 61, 344.

143. Loo, A. H.; Sofer, Z.; Bousa, D.; Ulbrich, P.; Bonanni, A.; Pumera, M.; ACS Appl. Mater. Interfaces 2016, 8, 1951.

144. Mansur, A. A. P.; Ramanery, F. P.; Mansur, H. S.; Mater. Chem. Phys. 2013, 141, 223.

145. Chen, Y. Y.; Cheng, B. R.; He, Z. B.; Wang, S. Y.; Wang, Z. M.; Sun, M.; Song, H. B.; Fang, Y.; Chen, F. F.; Xiong, B.; J. Cancer 2016, 7, 69.

146. Hong, G. S.; Robinson, J. T.; Zhang, Y. J.; Diao, S.; Antaris, A. L.; Wang, Q. B.; Dai, H. J.; Angew. Chem., Int. Ed. 2012, 51, 9818.

147. D’Amico, M.; Fiorica, C.; Palumbo, F. S.; Militello, V.; Leone, M.; Dubertret, B.; Pitarresi, G.; Giammona, G.; Mater. Sci. Eng. C 2016, 67, 231.

148. Hersel, U.; Dahmen, C.; Kessler, H.; Biomaterials 2003, 24, 4385.

149. Aubert, T.; Soenen, S. J.; Wassmuth, D.; Cirillo, M.; Van Deun, R.; Braeckmans, K.; Hens, Z.; ACS Appl. Mater. Interfaces 2014, 6, 11714.

150. Algar, W. R.; Krull, U. J.; Biosensing Using Nanomaterials, $7^{\text {th }}$ ed., Wiley: New York, 2009, cap. 7.

151. Mahjoub, M. A.; Monier, G.; Robert-Goumet, C.; Reveret, F.; Echabaane, M.; Chaudanson, D.; Petit, M.; Bideux, L.; Gruzza, B.; J. Phys. Chem. C 2016, 120, 11652.

152. Singh, K.; Chaudhary, G. R.; Singh, S.; Mehta, S. K.; J. Lumin. 2014, $154,148$.

153. Geng, S.; Lin, S. M.; Liu, S. G.; Li, N. B.; Luo, H. Q.; RSC Adv. 2016, 6, 86061 .

154. Li, H. B.; Wang, X. Q.; Sens. Actuators, B 2008, 134, 238.

155. Paramanik, B.; Bhattacharyya, S.; Patra, A.; Chem.-Eur. J. 2013, 19, 5980.

156. Singh, K.; Mehta, S. K.; Analyst 2016, 141, 2487.

157. Geng, S.; Lin, S. M.; Liu, S. G.; Li, N. B.; Luo, H. Q.; RSC Adv. 2016, 6, 86061 .

158. Deng, J.; Fu, Q.; Luo, W.; Tong, X.; Xiong, J.; Hu, Y.; Zheng, Z.; Sens. Actuators, B 2016, 224, 153.

159. Li, S.; Toprak, M. S.; Jo, Y. S.; Dobson, J.; Kim, D. K.; Muhammed, M.; Adv. Mater. 2007, 19, 4347.

160. Li, R.; Che, J.; Zhang, H.; He, J.; Bahi, A.; Ko, F.; J. Nanopart Res. 2014, 16, 2581.

161. Eita, M.; El Sayed, R.; Muhammed, M.; J. Colloid Interface Sci. 2012, 387, 135.

162. Nogueira, R. F. P.; Jardim, W. F.; Quim. Nova 1998, 21, 69.

163. Xu, X. Y.; Zhou, G.; Feng, B.; Bao, Z. J.; Hu, J. G.; Mater. Lett. 2016, $165,196$.

164. Ohtani, B.; J. Photochem. Photobiol. C: Photochem. Rev. 2010, 11, 157.

165. Regiel-Futyra, A.; Kus-Liskiewicz, M.; Wojtyla, S.; Stochel, G.; Macyk, W.; RSC Adv. 2015, 5, 80089.

166. Kazuhito, H.; Hiroshi, I.; Akira, F.; Jpn. J. Appl. Phys. 2005, 44, 8269.

167. Chen, T.; Yu, S.; Fang, X.; Huang, H.; Li, L.; Wang, X.; Wang, H.; Appl. Surf. Sci. 2016, 389, 303.

168. Lin, L.; Huang, J.; Li, X.; Abass, M. A.; Zhang, S.; App. Catal., B 2017, 203, 615 .

169. Tao, J.; Gong, Z.; Yao, G.; Cheng, Y.; Zhang, M.; Lv, J.; Shi, S.; He, G.; Jiang, X.; Chen, X.; Sun, Z.; J. Alloys Compd. 2016, 688, 605.

170. Zalfani, M.; van der Schueren, B.; Mahdouani, M.; Bourguiga, R.; Yu, W.-B.; Wu, M.; Deparis, O.; Li, Y.; Su, B.-L.; Appl. Catal., B 2016, 199, 187. 